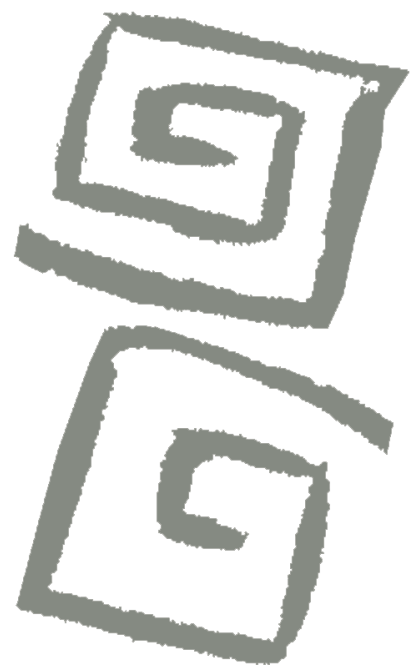

\title{
Desigualdades en salud: nuevas perspectivas teóricas
}

\section{Health inequalities: new theoretical perspectives}

Naomar de Almeida-Filho'

'PhD en Epidemiología. Investigador I-A del Conselho Nacional de Desarrollo Científico y Tecnológico (CNPq). Profesor Titular jubilado, Instituto de Saúde Coletiva, Universidade Federal da Bahia. Profesor Visitante, Instituto de Estudios Avançados Universidade de São Paulo, Brasil. $\triangle$ (iD)
RESUMEN En este texto pretendo articular la problemática teórica de las desigualdades económicas y sociales con la determinación social de la salud. Inicialmente presento una síntesis de las teorías de justicia y equidad de Rawls y Sen, que ilustran la perspectiva dominante de las epistemologías del norte. En segundo lugar, discuto aplicaciones de ese marco teórico en la bibliografía sobre desigualdades sociales y determinación social de la salud-enfermedad-cuidado. En tercer lugar, presento una propuesta de matriz semántica para la serie significante diferencia-distinción-desigualdad-inequidad-iniquidad, que contribuye a reducir la confusión terminológica existente. Luego, introduzco un modelo teórico sintético sobre el binomio pobreza-desigualdades, referenciado en los conceptos de recursos sociales, prácticas de salud, servicios de salud y situación-condiciones de salud. Finalmente, desde la perspectiva de las epistemologías del sur global, tomando la coyuntura brasileña actual como caso de estudio, discuto sus implicancias políticas relacionadas con la hipótesis de que está en curso un proceso de transformación de las desigualdades económicas con nuevas formas de inequidades sociales e iniquidades en salud.

PALABRAS CLAVES Factores Socioeconómicos; Determinantes Sociales de la Salud; Equidad en Salud.

\begin{abstract}
This article, I intend to articulate the theoretical problem of economic and social inequalities with the issue of the social determination of health. Initially, I provide a summary of Rawls' and Sen's theories of justice and equity as an illustration of the dominant perspective in Northern epistemologies. Second, I discuss applications of this theoretical framework in the literature on social inequalities and the social determination of health-illness-care. Thirdly, I present a semantic matrix proposed for the differencedistinction-inequality-inequity-iniquity series to help reduce the existing terminological confusion. Next, I introduce a synthetic theoretical model about the poverty-inequality dyad, referring to the concepts of social resources, health practices, health services, and health situation/conditions. Finally, oriented by an epistemological perspective from the global South, and taking the current Brazilian situation as a case study, I discuss political implications of the complex contemporary conjuncture, pertinent to the hypothesis that a process of transformation of economic inequalities into new forms of social inequities and health iniquities is currently underway.
\end{abstract}

KEY WORDS Socioeconomic Factors; Social Determinants of Health; Health Equity. 


\section{INTRODUCCIÓN}

Con el avance de los movimientos de la medicina social y de la salud colectiva, a partir de la década de 1980 se produjo un significativo incremento de la producción científica sobre desigualdades sociales, como determinantes de la situación de la salud en países de América Latina y el Caribe. En las últimas décadas del siglo XX, la Organización Panamericana de la Salud (OPS) manifestó un interés especial en este tema de investigación, principalmente cuando Pedro Luis Castellanos estuvo a cargo de la División de Salud y Desarrollo Humano. En 1998, propuso la creación del Grupo de Trabajo en Inequidades en Salud, que organizó un repositorio de textos y produjo una cartografía analítica de la producción académica sobre el tema ${ }^{(1,2)}$. Un análisis bibliométrico y de contenido de esos estudios encontró -en casi todos los países de la región- un predominio de abordajes doctrinarios o teóricos, en vez de investigaciones empíricas con datos epidemiológicos ${ }^{(3)}$. El análisis de los marcos referenciales de esos estudios mostró una clara hegemonía de abordajes vinculados al materialismo histórico, con especial énfasis en los procesos de producción (condiciones de trabajo) y reproducción (estructura de clases) de la sociedad ${ }^{(4)}$.

En este período, en todos los países del mundo se constataron disparidades en las condiciones de salud, acceso diferencial a los servicios asistenciales y distribución desigual de recursos de salud, independientemente del grado de desarrollo económico y del régimen político ${ }^{(5,6,7)}$. Como resultado, se produjo una inesperada revitalización de la epidemiología social, especialmente abocada a la obtención de datos empíricos, lo que fomentó casi un monopolio del tema "desigualdades" en la epidemiología social contemporánea ${ }^{(8)}$. El vector central de esas investigaciones enfatizaba temas clásicos de la investigación social en salud, como el estrés, la pobreza, la miseria, la exclusión social y la marginalidad, incorporados a la agenda de investigación como efecto de las desigualdades económicas y sociales. Así, el pensamiento epidemiológico moderno se actualizaba sobre la base de una perspectiva neo-durkheimiana y se consolidaban dos vertientes explicativas de la génesis social de la salud-enfermedad-cuidado: una, en América del Norte, que utilizaba conceptos como capital social, apoyo social y estrés psicosocial ${ }^{(5,6,7,7,9)}$ y otra, en Europa, con conceptos como estratificación social, cohesión social y estilo de vida ${ }^{(6,7,10,11)}$.

En contraste con la situación observada en América Latina y el Caribe, los estudios sobre desigualdades en salud de los países del hemisferio norte revelaban poco interés en la formulación teórica ${ }^{(12,13)}$. Como estrategia para cubrir tal laguna, Diederichsen, Evans y Whitehead propusieron una "combinación de pensamiento claro (clear thinking), datos de buena calidad y una política de movilización"(12). En otras palabras, era necesario enfrentar, simultáneamente, una cuestión teórica, una problemática metodológica y un desafío político. Considerando que, en los países Ilamados desarrollados, los referenciales teóricos de la epidemiología social eran escasos y carecían de un punto de vista conceptual, Nancy Krieger hizo una clara advertencia: "If social epidemiologists are to gain clarity on causes of and barriers to reducing social inequalities in health, adequate theory is a necessity, not a luxury" [Si los epidemiólogos sociales buscan aclarar las causas y las barreras para reducir las desigualdades sociales en salud, una teoría adecuada es una necesidad, no un lujo] ${ }^{(13)}$.

Para analizar mejor esa pobreza teórica potencial y eventualmente contribuir a superarla, necesitamos reconsiderar qué constituye una teoría, según el abordaje propuesto por el filósofo argentino Juan Samaja (19412007). Desde la perspectiva pragmático-crítica ${ }^{(14,15)}$, una teoría comprende un dispositivo heurístico, configurado en tres etapas o fases:

- Marco referencial filosófico: epistemología, lógica y método.

- Proceso de problematización: definición del objeto de conocimiento y construcción de conceptos, incluyendo terminología.

- Marco teórico: modelo y modelado (determinantes, efectos, incluso mensuración). 
En este texto, propongo un recorte de la problemática teórica de las desigualdades, como paso inicial para formular de modo sistemático y con mayor precisión, quizá como "pensamiento claro", su articulación con el problema de la determinación social de la salud. El análisis está centrado en cómo se ha realizado el proceso de construcción teórica en la bibliografía sobre desigualdades en salud, concediendo especial atención al rigor conceptual $y$, en consecuencia, a la formulación de una estructura terminológica adecuada y específica. En este recorrido, serán pertinentes e incluso inevitables las correlaciones, remisiones y referencias a la problemática metodológica de las desigualdades en salud para formular proposiciones $y$, eventualmente, sustentar los argumentos $^{(15)}$. A pesar de que la problemática política de las desigualdades sea constitutiva del modo de producción capitalista, sobre todo en el contexto neoliberal actual ${ }^{(16)}$, será tratada aquí de un modo transversal, dado que su abordaje puntual y profundo escapa al interés central de este texto.

Con este objetivo, inicialmente pretendo resumir el principal marco teórico que, en los países desarrollados, ha subsidiado la producción académica sobre el tema desigualdades en salud. Como ilustración de la robustez ( $y$, dialécticamente, de las limitaciones) de la perspectiva dominante de las epistemologías del norte global, presento una síntesis, limitada y breve, de la teoría de la justicia de John Rawls y de su principal derivación: la teoría del bienestar social de Amartya Sen. En segundo lugar, discuto interpretaciones, aplicaciones y abordajes críticos de ese marco teórico en la bibliografía académica que aborda las desigualdades económicas y sociales como principal eje, para comprender la determinación social de la salud-enfermedad-cuidado. En tercer lugar, pretendo sistematizar una propuesta de matriz semántica para la serie conceptual < diferencia-distinción-desigualdad-inequidad-iniquidad $>$, con la intención de contribuir a reducir la confusión terminológica que, en mi evaluación, representa un importante obstáculo para una reflexión teórica más rigurosa sobre el tema.
A continuación, para comprender el impacto de los procesos y vectores generados por las desigualdades económicas, sociales y políticas en el campo de la salud, recupero un modelo teórico sintético sobre el binomio pobreza-desigualdades, referenciado en las categorías de recursos sociales, modos de vida, prácticas de salud, servicios de salud y situación/condiciones de salud. Finalmente, tomando la coyuntura brasileña actual como caso de estudio, propongo la hipótesis de que estamos ante un proceso de transformación de las desigualdades económicas en nuevas formas de inequidades sociales e iniquidades en salud. Al sistematizar dos décadas de debates y reflexiones, espero contribuir a la discusión teórico-metodológica pertinente al estudio de las desigualdades, en general, y de las iniquidades en salud, en particular, desde una perspectiva de las epistemologías del sur global.

\section{JUSTICIA, EQUIDAD, IGUALDAD: DE RAWLS A SEN}

En la segunda mitad del siglo XX, el filósofo político estadunidense John Rawls (19212002) propuso una teoría de la justicia que considera la categoría "libertades básicas" como definidora de la autonomía individual, en una perspectiva neokantiana ${ }^{(17,18,19)}$. Rawls presenta su concepción general de la justicia como estructurante de la sociedad contemporánea, con base en dos principios ${ }^{(17)}$ :

Primer principio: cada persona debe tener un derecho igual al esquema más extenso de libertades básicas iguales, compatible con un esquema similar de libertades para otros.

Segundo principio: las desigualdades económicas y sociales deben distribuirse de tal manera que: a) las desigualdades proporcionen el mayor beneficio a los menos aventajados, dentro de los límites de un justo respeto al principio del ahorro (de los más aventajados); y b) las 
desigualdades correspondan a funciones y puestos que estén abiertos a todos según el principio de una justa igualdad de oportunidades.

Para Rawls, en la sociedad moderna, el concepto de justicia implica un sistema de prioridades que justificaría sucesivas elecciones personales y políticas definidas por valores, bienes y productos en disputa. Si los agentes sociales eligen un bien en detrimento de otro es porque existirían razones prácticas para considerarlo más deseable y prioritario que el otro. La intención declarada de ese enfoque es criticar y de algún modo actualizar el programa político del utilitarismo de John Stuart Mill(20).

El primer principio de Rawls, en el marco de consolidación del capitalismo mercantil y del surgimiento del capitalismo industrial ${ }^{(16)}$, corresponde a la máxima fundamental del liberalismo clásico, plataforma política subsidiaria de la doctrina económica de las revoluciones republicanas de EEUU, en 1776, y de Francia, en 1789. El segundo principio evoca dos reglas de prioridad: prioridad de la libertad plena sobre las libertades básicas y prioridad de la justicia sobre la eficiencia económica y el bienestar individual ${ }^{(17)}$. De acuerdo con la primera regla, los principios de justicia deben ser ordenados de modo socialmente legítimo y justo y, por lo tanto, las libertades básicas individuales pueden ser restringidas solo en beneficio de una libertad para todos. En este caso, pueden ocurrir dos situaciones: 1) tolerar alguna restricción de la libertad individual para reafirmar el sistema compartido y colectivo de libertad; 2) tomar las desigualdades como aceptables solo en el sentido positivo, en beneficio de aquellos a quienes se atribuye desventajas. Según la segunda regla, el principio de justicia es prioritario frente a los principios de eficiencia y de maximización de la suma de beneficios, del mismo modo que el principio de igualdad equitativa de oportunidades tiene prioridad sobre el principio de diferencia. Por lo tanto, la teoría de la justicia de Rawls propone igualdad de oportunidades y también de distribución justa -es decir, con justeza (fairness) - de bienes y servicios referentes a necesidades básicas ${ }^{(21)}$.

A pesar de que la salud tenga gran presencia en la bibliografía sobre desigualda$\operatorname{des}^{(5)}$, curiosamente Rawls no la menciona como una de las libertades básicas, incluida entre los derechos humanos fundamentales. Por el contrario, la salud es definida como un bien natural, en la medida en que forma parte de los recursos (endowments) innatos de los individuos. Diversos estudiosos pretendieron cubrir esa laguna, desarrollando variantes y complementos del abordaje rawlsiano aplicado al problema de las desigualdades en salud. El más destacado de estos autores es el economista indobritánico Amartya Sen, que ganó el Premio Nobel de Economía de 1998 por haber actualizado la ciencia económica frente a las transformaciones políticas y sociales posteriores al advenimiento del Estado de bienestar social, en la segunda mitad del siglo XX. Una parte significativa de su obra ${ }^{(22,23,24,25)}$ conforma lo que devino en Ilamarse new social-welfare theory (NSWT), una reflexión teórica sobre las desigualdades económicas que se ha tornado hegemónica en la investigación sobre determinantes sociales en salud.

En una serie de conferencias en la Universidad de Warwick (The Radcliff Lectures, en 1972), reunidas en On economic inequality ${ }^{(22)}$, Amartya Sen se propuso enriquecer la teoría de la elección social, a partir de una crítica a los abordajes utilitaristas. Con base en la premisa de que la economía habría sido creada para servir de instrumento social y satisfacer las necesidades humanas, Sen define "bienestar social" como efecto de procesos políticos de redistribución de la riqueza, y no como efecto de apropiación de la riqueza por parte de individuos o grupos. Al proponer el concepto de desigualdades (inequalities) de propiedad, ingresos y riqueza como contraste operativo y cuasisimétrico al concepto de bienestar social, advierte que "no se debe confundir igualdad con simetría"(22).

Tomando como referencia el postulado de justicia distributiva de Rawls, Sen formula un axioma débil de la equidad (weak equity axiom): 
Sea que la persona i tenga un nivel de bienestar menor que la persona j para cada nivel de ingreso individual. Entonces, al distribuir un ingreso total dado entre $\mathrm{n}$ individuos que incluyen a i y j, la solución óptima debe dar a i un nivel de ingreso mayor que a j. [Traducción de: Let person $i$ have the lower level of welfare than person $j$ for each level of individual income. Then in distributing a given total of income among $n$ individuals including $i$ and $j$, the optimal solution must give $i$ a higher level of income than j]. ${ }^{(22)}$

Al proponer una base formal para indicadores de concentración desigual de ingresos, Sen sugiere una tipología dicotómica para las desigualdades: desigualdad objetiva y desigualdad normativa. Desde el punto de vista de la desigualdad objetiva, equivalente a la variación relativa del indicador económico de ingresos, la cuestión de la diferenciación entre dos elementos $x$ e y implica comparabilidad en escalas cardinales de orden equivalente. En esas escalas, no habría ningún problema en formular descriptivamente las desigualdades $x>$ y o $x<y$, tal como se expresa a continuación:

$$
\begin{aligned}
& x_{1}>x_{2}>x_{3}>\ldots>x_{n} \\
& y_{1}>y_{2}>y_{3}>\ldots>y_{n}
\end{aligned}
$$

Por otro lado, la noción de desigualdad normativa -contradominio del concepto de bienestar social- remite a la distribución de un valor dado (por ejemplo, ingresos) entre dos elementos x e y, de modo ecuánime. Tal dualidad permite una concepción metodológica integrativa de las desigualdades económicas, con doble alcance: objetivo y normativo. A partir de este análisis, Sen evalúa críticamente dos alternativas redistributivas:

- Igualitarismo tipo maximin, correspondiente a la teoría de la justicia de Rawls;

- Igualitarismo probabilístico, con base en el principio de la equiprobabilidad.

Para Sen, esa categorización de la desigualdad permitiría formalizar el problema de la justicia distributiva con base en una solución lógica, ética y política, capaz de generar equidad entre desiguales. Tal problema abstracto puede ser ilustrado por el ejemplo concreto de la división justa de una torta: ¿cómo dividir una torta entre dos individuos, dado que ellos no son iguales en la línea de base? ¿Cómo dividir 100 por 2, una parte para $x$ y una parte para $y$ ? Varias opciones pueden servir de solución:

$$
50 x, 50 y ; 51 x, 49 y ; 52 x, 48 y ; \ldots 99 x, 1 y
$$

Se trata de un problema clásico de elección social (social choice) para soluciones de equidad distributiva, como posibilidad de remediar desigualdades preexistentes. Sin embargo, desde el punto de vista normativo, el problema no se resuelve solo fijando criterios abstractos de valor; de hecho, depende de la aceptabilidad o legitimación social de la solución distributiva elegida. Como consecuencia, se deben considerar los aspectos de valor económico versus legitimidad social. En este sentido, Sen evalúa cinco condiciones que permiten ordenar las prioridades de elección.

- Anarquía o dominio irrestricto: se admite cualquier combinación.

- Individualismo o independencia de alternativas irrelevantes: lo social depende de lo individual.

- Preferencia social completa y reflexiva: elección cuasitransitiva.

- Anonimato: cambio de orden individual no afecta la preferencia social.

- Regla de Pareto: para cualquier par $(x, y)$, si todos los individuos creen que $x$ es por lo menos tan bueno como $y$, mientras algunos consideran que $x$ es mejor que $y$, entonces $x$ es socialmente más preferido que $y$; si es indiferente para todos, así también lo será para la sociedad.

Sen concluye que la condición más adecuada para soluciones distributivas superadoras de desigualdades es la regla de Pareto. EI presupuesto de esa regla es que la sociedad se condice, por lo menos, a la suma de los individuos y que, por lo tanto, la preferencia social también comprende, por lo menos, la 
suma de preferencias individuales. Su conclusión contradice la teoría económica clásica, al plantear que el utilitarismo, enfoque dominante de la "vieja economía liberal, tendiente a producir resultados fuertemente antiigualitarios (anti-egalitarian)", no es capaz de pensar el problema de la distribución equitativa de bienes y riquezas ${ }^{(22)}$.

Para viabilizar soluciones metodológicas al problema teórico de la naturaleza simultáneamente objetiva (descriptiva) y normativa (política y ética) de las desigualdades económicas y sociales, Sen propone relativizar la medida de las desigualdades. Para eso, postula dos estrategias complementarias: por un lado, combinar normatividad y descriptividad $y$, por otro, recurrir a ordenamientos parciales.

Al considerar elementos estructurales de la noción de desigualdades sociales, Sen propone recuperar, con ciertas reservas, la noción de plusvalía de Karl Marx (18181883) como fundamento para modelos de retribución por mérito más eficientes que las políticas de distribución basadas en necesidades. Analiza el texto de Marx Crítica del Programa de Gotha ${ }^{(26)}$ del cual transcribe extensos fragmentos, en los que encuentra una negación de la noción de derechos iguales como "derecho de desigualdad", que él identifica como una pseudoequidad. Dentro de esa línea argumentativa, propone el concepto de capabilities (fusión de capacidades con habilidades) como criterio para priorizar la lógica distributiva a partir del mérito individual.

En su crítica, Sen ya no considera que la obra de $\mathrm{Marx}^{(26,27)}$, más que proponer un sistema teórico explicativo, pretendía denunciar situaciones y analizar estructuras con la intención de movilizar y transformar contextos. Si bien las nociones de desigualdades económicas y sociales tienen prioridad en la construcción de la teoría marxista de la sociedad capitalista y, por consiguiente, de la teoría política de la historia, Marx trató esa cuestión siempre analíticamente (es decir, apuntando a comprender la génesis de las relaciones sociales para transformarlas). Pero a pesar de referirse al concepto de "clases sociales" como raíz de las disparidades económicas y políticas que orientaron el conjunto de teorías marxistas de la sociedad, Marx no profundizó el debate sobre la naturaleza y las modalidades de las desigualdades. De hecho, Marx no estaba interesado en ayudar al capitalismo a humanizarse y que, de esa forma, se viabilice como ideología. Su proyecto científico era investigar profunda y detalladamente el modo de producción del capitalismo a fin de formular una propuesta política capaz de transformar radicalmente (por ejemplo, desde las raíces) la estructura de la sociedad capitalista, entendiendo las desigualdades económicas como el fundamento de procesos de determinación social y no como un mero epifenómeno, disfrazadas de variables o vectores, indicadores de inequidades inevitables.

Al igual que otros clásicos como El capital de Marx ${ }^{(27)}$, On economic inequality de Sen es una opera prima inconclusa. En su parte final, que reproduce la cuarta conferencia Radcliff, confronta nociones rivales heredadas de las viejas escuelas de economía política sobre cómo debería estar constituida una distribución correcta o justa: ¿orientada por necesidades o de acuerdo con méritos y motivaciones? Como si fuese a retomar su argumento (que, sin embargo, sigue incompleto), Sen señala que la distribución basada en el mérito (desert-based) y sus variantes -propuestas redistributivas orientadas por motivaciones-, no parecen apropiadas para reducir las desigualdades. Su análisis converge hacia una posición, insuficientemente justificada y apresuradamente finalizada, a favor de una distribución orientada por necesidades.

Cabe ahora apreciar la reorientación, casi autocrítica, que Amartya Sen realiza en trabajos más recientes ${ }^{(23,24)}$. La cuestión crucial del primero de estos textos complementarios es: ¿desigualdad de qué? Como aplicación metodológica, introduce una variante en el uso de esa concepción, e identifica variables focales relevantes (como, por ejemplo: desigualdad de ingresos, riquezas, utilidades, recursos, libertades, derechos, calidad de vida, etc.). En este aspecto, en una curiosa convergencia con la sociología de la distinción de Bourdieu $^{(28)}$, sin darle crédito, Sen introduce 
el problema del "gusto desigual" (unequal taste) y considera su tratamiento analítico como potencialmente interesante para estudiar variaciones salariales y fijación de precios de productos. Desde el punto de vista conceptual, propone considerar una cuestión correlativa: ¿desigualdad dónde? Explicita entonces la concepción de "espacio para la equidad" y su noción derivada de "espacio evaluativo" de las desigualdades. Argumenta que si todas las personas fueran exactamente similares, la igualdad en el espacio económico (por ejemplo, en los ingresos) tendería a ser congruente con igualdades en otras dimensiones (salud, bienestar, felicidad, etc.) ${ }^{(23)}$.

Así, Amartya Sen retoma el planteo de que las desigualdades pueden ser resultantes de cuasiordenamientos (quasi-ordering) en la estructura de la sociedad, que expresan de modo más preciso jerarquías o prioridades en espacios diversos o dimensiones simultáneas. En la teoría económica convencional se postula que "una de las consecuencias de la diversidad humana es que la igualdad en un espacio tiende a corresponder, de hecho, con la desigualdad en otro"(23). Anticipando controversias en el tratamiento de esa cuestión, Sen considera que desigualdad en términos de una variable (por ejemplo, riqueza) puede indicar un sentido muy diferente de desigualdad en el espacio de otra variable (por ejemplo, habilidad funcional o bienestar). Cabe aquí la hipótesis de que promover la equidad en un espacio dado puede generar desigualdades en otros espacios sociales.

En un prefacio escrito en colaboración con James Foster ${ }^{(24)}$, Sen avanza en la desconstrucción de los indicadores clásicos de desigualdades a partir de una crítica epistemológica del propio concepto de "indicador". Para Foster y Sen, la precisión descriptiva (definida como conjunto de aserciones totalmente ordenadas y no ambiguas, independientemente de la ocurrencia de inconsistencias en los conceptos de base) sería deseable para evaluar las desigualdades. Al constatar que el concepto de desigualdad porta una ambigüedad de origen, asumen que los indicadores necesarios para tratar empíricamente un concepto ambiguo no deben aferrarse a una representación precisa, pero ilusoria, de los fenómenos estudiados ${ }^{(24)}$. Al contrario, es necesario preservar algún grado de incertidumbre primordial, en vez de intentar desterrarla mediante ordenamientos arbitrarios.

Este último ajuste en su teoría permite considerar especificidades o contextos parciales en la relativización de las desigualdades y admitir que estas pueden asumir un carácter contingente, dialéctico o incluso ambiguo. Al dar espacio a la cuestión política y la acción individual, societal o comunal, intenta responder a las críticas iniciales vinculadas al exceso de economicismo de la NSWT, que tomaba movimientos estructurales y macrotendencias como determinantes del bienestar social. En este sentido, se aproxima a las perspectivas críticas que proponen que la dinámica de los sistemas económicos puede comprenderse mejor a través de la esfera político-ideológica, como lo hizo recientemente Thomas Piketty al afirmar que, en el contexto actual, al que denomina hipercapitalismo, l'économie est au coeur de la politique ${ }^{(29)}$.

\section{CONCEPTOS DE DESIGUALDADES EN SALUD}

En esta sección, buscaré revisar brevemente las principales aplicaciones de la temática desigualdades/inequidades en la bibliografía específica del campo de la salud. En esos abordajes, típicos de lo que Boaventura de Sousa Santos ${ }^{(30,31)}$ designa como "pensamiento abisal", o epistemologías del norte, la salud ha sido tratada conceptualmente como una especie peculiar de capital humano, entendida a partir de variantes o derivaciones de los conceptos de endowment o de capability.

Amartya Sen utiliza numerosos ejemplos del campo de la salud en dos planos. En el primer plano, propone considerar conceptos de justicia y equidad como base para la elección social de estrategias redistributivas para superar las desigualdades en salud(25). Particularmente en Inequality reexamined ${ }^{(23)}$, Sen reconoce la centralidad del concepto de 
equidad en el campo de la salud y destaca el potencial de ese campo como espacio privilegiado para políticas redistributivas, en una lógica de bienestar social. Dentro de esa línea, considera los sistemas públicos de atención de la salud como parte del aparato del welfare state, definido en la esfera institucional como campo de posibilidades de compensación que apuntan a la equidad. Indica, entonces, que un servicio nacional de salud compone un sistema de justicia distributiva indirecta, comparable a otros sistemas de justicia definidos por la distribución directa de subsidios.

En el segundo plano, Sen define la salud individual como efecto de capabilities ${ }^{(23,24)}$. Este sustantivo, de difícil traducción al español, trae consigo el doble sentido de "capacidad" y "habilidad" como potenciales competencias. Desde una perspectiva semántica, representa una valiosa indicación para una construcción rigurosa del concepto de salud, como señalé en otro texto ${ }^{(32)}$. El problema se muestra más intrigante y la construcción teórica potencialmente más rica si consideramos otras diferencias de base individual, más allá de las capabilities, que conformarían ese complejo objeto de conocimiento llamado salud.

En 1990, Margareth Whitehead elaboró un informe encargado por la Organización Mundial de la Salud, posteriormente publicado en el International Journal of Health Services ${ }^{(33)}$ que fue por mucho tiempo la principal referencia conceptual sobre equidad en salud de la bibliografía internacional. La premisa básica de ese texto es que la equidad en salud equivaldría al concepto de justicia, en lo que se refiere a la situación de salud, calidad de vida y supervivencia individual. De esa forma, idealmente, todas las personas tendrían derecho a la posibilidad de realizar su pleno potencial de salud $y$, para realizar ese derecho, nadie debería estar en desventaja. En términos prácticos, esa aproximación Ilevaría a reducir, al máxima posible, las desigualdades en el acceso a los servicios de salud y en las condiciones de salud ${ }^{(34)}$.

Como contribución a esta problemática conceptual, Whitehead define equidad (equity) con relación a dos antónimos que denotan modalidades de disparidades (disparities) en salud: desigualdad (inequality) e inequidad (inequity) ${ }^{(33)}$. Para la autora, el primer término -desigualdad- en todos los casos connota las principales diferencias dimensionales, mensurables, sistemáticas y evitables, entre los miembros de una populación dada. Este término, al ser usado a menudo en un sentido formal, puramente matemático o epidemiológico, por su ambigüedad, según la autora, no debe ser utilizado como concepto de base para el análisis político de la situación de salud. En contrapartida, el segundo término inequidad-connota diferencias y variaciones que son no solo innecesarias y evitables, sino también injustas. En este sentido, las inequidades en salud pueden ser definidas como modalidades restrictas o algún caso particular de diferencias o disparidades en salud que, además de evitables (avoidable), son también injustas (unfair) ${ }^{(33)}$. De esta forma, el concepto se conforma a partir de criterios relevantes para identificar la doble condición de evitabilidad y de injusticia inherente a la imposición de los riesgos, excepto en dos situaciones: exposición voluntaria (comportamientos de riesgo, deportes peligrosos, contingencias especiales) y riesgo estructural inevitable (edad, sexo, genética) ${ }^{(34)}$.

La contribución de Whitehead, representativa del linaje teórico Rawls-Sen, se basa en una concepción idealizada de justicia como principal parámetro para distinguir entre inequidades y diferencias (o disparidades) en salud. No obstante la aparente consistencia conceptual, varios autores ${ }^{(35,36,37)}$ emplean este referencial de forma equivocada pues, para delimitar el concepto de inequidad, toman el término desigualdad como sinónimo de diferencia o disparidad. Curiosamente, esa inestabilidad semántica está presente incluso en textos de la propia Whitehead ${ }^{(8,33,34)}$.

Daniels, Kennedy y Kawachi ${ }^{(38)}$ propusieron retomar la teoría de justicia de Rawls para analizar la distribución de la salud en una sociedad igualitaria, definida por ellos como aquella donde el acceso a la salud no se determina por el estatus social o por los ingresos económicos. Estos autores cuestionan la definición de inequidad de Whitehead 
sobre la base de los criterios de injusticia y evitabilidad, con el argumento de que ambos conceptos involucran cuestiones complejas y no resueltas. Respecto al primer criterio, toman como base la noción liberal de autonomía, que define "justicia" como una garantía nominal de igualdad de oportunidades individuales ${ }^{(38)}$. Con relación al segundo criterio, Peter y Evans ${ }^{(39)}$ desarrollaron teóricamente la idea de justicia como fundamento del derecho universal a la salud, entendido como equidad también en el acceso al conocimiento y la tecnología, factores que definen el grado de evitabilidad de los problemas de salud.

En la conferencia ¿Por qué la equidad en salud?(25), el propio Sen propuso que la equidad es un concepto simultáneamente multidimensional e intersectorial, especialmente si se aplica a la salud. En lo referente a su multidimensionalidad, incluye desde aspectos más estrictamente epidemiológicos -como riesgos de enfermarse o probabilidades de tener buena salud-, hasta la "distribución de la atención sanitaria, [...] la justicia de los procesos y, por lo tanto, la ausencia de discriminación en la prestación de la asistencia sanitaria". En este sentido, afirma que "ciertamente, la equidad en salud no trata solo de la distribución de la salud, por no hablar del campo todavía más limitado de la distribución de la asistencia sanitaria"(25). Refuerza así el carácter intersectorial de la salud, al afirmar que la equidad en salud extrapola el campo de la salud, incluyendo el tema de la distribución de recursos económicos y considerando el papel crucial de la salud en la vida y en la libertad humanas ${ }^{(40)}$, para alcanzar "el ámbito más amplio de la justicia de los acuerdos sociales"(25).

Macinko y Starfield ${ }^{(41,42)}$ concluyen que hacer que justicia sea equivalente al concepto de equidad, como defienden Whitehead et al., trae problemas operacionales en la medida en que implica recurrir a "juicios de valor". Proponen usar la definición establecida por la International Society for Equity in Health (ISEqH), según la cual "equidad" es la ausencia de diferencias sistemáticas potencialmente evitables o curables en uno o más aspectos de la salud, en grupos o subgrupos poblacionales definidos social, económica, demográfica o geográficamente ${ }^{(43)}$. Esta concepción, al distanciarse de la proposición de Whitehead, evita la distinción respecto de la igualdad, al definir la equidad como mera "ausencia de diferencias". A pesar de eso, la definición de equidad del ISEqH tiene ventajas operacionales, pues desvía el problema de las diferencias hacia el ámbito del control técnico (diferencias potencialmente curables), lo que permite algún grado de estandarización metodológica de las investigaciones sobre situaciones de desigualdad ${ }^{(44)}$.

Desde este abordaje instrumental, que valora la mensuración más que la teorización, algunos economistas de la salud también contribuyeron a la problemática conceptual de las desigualdades. Al admitir que la salud es más difícil de medir que los ingresos (y, por extensión, el bienestar social), Wagstaff y Van Doorslaer $^{(45)}$ consideran que los indicadores de salud pueden ser reducidos a escalas lineales, tomando como ejemplo la expectativa de vida. Posteriormente, al alinearse con la teoría del bienestar social de Sen y argumentar que los ingresos pueden ser medidos en escalas lineales, estos autores propusieron definiciones contrastantes: "desigualdades puras en salud" y desigualdades socioeconómicas en salud $^{(5)}$. En este abordaje, el adjetivo "puro" indica un foco exclusivo en la distribución de la propia variable de salud dentro de una población. Para estos autores ${ }^{(4,45)}$, la cuestión de las desigualdades como objeto de conocimiento se reduciría a la verificación de si tal distribución se encuentra de alguna manera determinada (social, biológicamente) o no (se distribuye de modo aleatorio). En su análisis, curiosamente, parecen desconocer los avances de la metodología epidemiológica para comprender procesos determinísticos en salud, correlacionando factores y exposiciones asociados en modelos matemáticos y estadísticos de determinación de riesgos condicionados por desigualdades sociales ${ }^{(12,46)}$.

Bommier y Stecklov ${ }^{(47)}$ recuperan las ideas de Rawls para criticar la propuesta de Whitehead, considerada de corto alcance, porque las "diferencias evitables deben ser reducidas o eliminadas"(47). En esa línea, propusieron 
una formalización basada en la definición de "acceso a la salud" como una libertad básica rawlsiana, la cual, combinada con los endowments específicos de la salud, se constituye en capacidad social de promover salud. Parten de la premisa de que el acceso (A) al estado de salud no es directamente mensurable. También consideran que el estatus de "salud real" (actual health) (H) puede ser evaluado a nivel individual, pero no hay información disponible para evaluar los recursos individuales de salud (health endowments) (E). Postulan, además, que la salud poblacional puede ser medida unidimensionalmente con un coeficiente como el de Gini, equivalente al generado por la medida de concentración de ingresos (Y). La conclusión es que, incluso en la sociedad igualitaria ideal pensada por Rawls, o en la utopía de la redistribución políticamente acordada de la sociedad de bienestar de Sen, donde el acceso (A) estaría garantizado para todos como derecho fundamental, cualquier correlación de $(\mathrm{Y})=>(\mathrm{H})$ necesariamente implicaría "desigualdad en salud" como efecto lógico de la función residual (E), sustrato individual de salud.

Por último, esa generación de economistas de la salud ${ }^{(5,11,12,22,45,47)}$ toma ingresos, producción, consumo y otros indicadores económicos como el principal (y tal vez ideal) parámetro para medir las desigualdades en salud en la sociedad. En este aspecto, presentan derivaciones de la función clásica de desigualdad de ingresos, basada en la NSWT de Sen, con importantes limitaciones conceptuales que, desde mi perspectiva, permiten identificar dos falacias: la falacia econocéntrica y la falacia econométrica.

La falacia econocéntrica asume que la esfera de la economía puede ser tomada como referencia dominante de la sociedad y que, por lo tanto, los dispositivos de explicación de la dinámica económica de las sociedades serían adecuados para comprender los procesos y los objetos de conocimiento sobre la salud y la vida social. Aunque tal posición pueda ser relativamente adecuada para economías industriales avanzadas (aquellas del mítico pleno empleo, antes de las actuales crisis del capitalismo), los ingresos no parecen representar una medida válida y plena de acceso al bienestar social y a los recursos de la vida en países pobres (incluyendo la salud). Más allá de la concentración de la riqueza, en sociedades flageladas por la pobreza, el desempleo y la exclusión social, se encuentran activas otras desigualdades derivadas de la categorización social, mediante estructuras y dinámicas propias ${ }^{(29)}$.

La falacia econométrica implica considerar que los procesos de producción de salud, de relaciones sociales y de mercancías son relativamente isonómicos y que, en consecuencia, las metodologías econométricas serían adecuadas para aprehender variaciones y disparidades en determinantes y efectos sobre la salud en la sociedad. Tal como señalan Kawachi, Subramanian y AlmeidaFilho $^{(48)}$, los abordajes dimensionales pueden ser válidos para productos y otros recursos del mercado; sin embargo, los fenómenos de la salud-enfermedad-cuidado tienen atributos y propriedades de producción, realización y distribución totalmente diferentes (y no reductibles) a los activos económicos.

La refutación de ambas falacias, con base en el argumento de que el abordaje NSWT de Sen sería inconsistente con la noción básica de distribución justa o equitativa de la salud, se sustenta en la constatación casi trivial de que la salud no puede ser linealmente producida, acumulada, invertida o redistribuida del mismo modo que los ingresos. De hecho, en el campo de la salud, existen serios impedimentos éticos y políticos para intervenciones de tipo redistributivo. Lo que sería una deuda social de la salud, como veremos más adelante, no puede ser objeto de políticas focales pues, en una concepción ética rigurosa, no se le puede sacar salud a una persona (rica) para darle a otra (pobre).

Pasando por alto las cuestiones conceptuales o incluso estrictamente terminológicas, cruciales para la apreciación rigurosa del tema, esos abordajes economicistas no revelan ninguna preocupación desde el punto de vista epistemológico, teórico o político. Además, las curvas de concentración de las desigualdades en salud o los índices de salud tipo Gini constituyen meras aplicaciones 
de las medidas de distribución de parámetros individuales, como estatus de salud o capacidad individual de acceso a recursos de salud, sin considerar los efectos agregados en poblaciones o grupos sociales.

Esa discusión fue recientemente retomada por Paula Braveman ${ }^{(49,50)}$ y por Arcaya, Arcaya y Subramanian ${ }^{(51)}$, quienes convergen en la crítica de cómo las desigualdades en salud han sido comúnmente analizadas, no solo por disparidades entre países, estados y divisiones geográficas, sino también mediante diferenciación de ingresos, estratos sociales y agrupamientos societales, definidos por raza/ etnia, género, educación, ocupación y otros. Los gradientes de salud por recortes de naturaleza social, cultural y política son típicamente reacios al mecanicismo simplificador del pensamiento econométrico y pueden ser comprendidos mejor desde perspectivas sociológicas y antropológicas. En este registro crítico, estos autores ${ }^{(48,49,50,51)}$ destacan los méritos de políticas específicas de erradicación de las desigualdades en salud, en comparación con aquellas que buscan elevar el patrón general de salud de una sociedad dada.

No obstante el potencial crítico de cierta anatomía del economicismo en salud, cabe aquí reducir el foco y explicitar de modo transparente que debemos abordar el lenguaje como un aspecto crucial para la construcción teórica de las desigualdades en salud, lo que denominaremos como "problemática terminológica".

\section{PROBLEMÁTICA TERMINOLÓGICA}

Según Samaja ${ }^{(14)}$, una buena teoría (válida, comprensiva, efectiva, pertinente, consistente, etc.) debe implicar necesariamente claridad y precisión terminológica. Con una mirada crítica, orientada a partir de las epistemologías del sur ${ }^{(30,31)}$, pretendo aquí mostrar que este no es el caso de la bibliografía sobre las relaciones entre desigualdades y salud. Retomando dos décadas de investigación conceptual ${ }^{(3,32,44,48,52,53)}$ quisiera compartir una reflexión crítica centrada en la matriz discursiva de las desigualdades.

Algunas de las contribuciones de los autores analizados pueden ser útiles para establecer una terminología más precisa sobre las desigualdades en salud. Se trata aquí de proponer un marco semántico común, paso inicial para una formulación teórica consistente y rigurosa, imprescindible para viabilizar mejores prácticas de investigación sobre el tema.

En primer lugar, siempre siguiendo a Samaja ${ }^{(14)}$, comencemos explicitando una posible definición preliminar (aparentemente simple, desde el punto de vista epistemológico) de objeto de indagación o de conocimiento:

$$
\begin{aligned}
& \text { Objeto = concepto }+ \text { cosa (evento, pro- } \\
& \text { ceso, fenómeno) }
\end{aligned}
$$

Para alcanzar el grado de claridad y precisión necesario y posible, propongo un recorte más, que intenta formular una respuesta viable a la pregunta de Sen "¿desigualdad de qué?". La respuesta simple y directa es que nuestro objeto sería "desigualdades en salud". No abordo la ontología implícita de este objeto particular del conocimiento, por ejemplo, en la pregunta de si la desigualdad en salud constituye una cosa y, por lo tanto, tiene materialidad, o si representa un mero efecto inmaterial. Sin embargo, en la secuencia, pretendo delimitar la estructura discursiva y la dimensión conceptual del objeto desigualdad (como también sus correlativos) como el punto central de este análisis.

Los conceptos son dispositivos lingüísticos que dan sustento al objeto de conocimiento, también definidos como términos en la estructura de un argumento dado ${ }^{(14)}$. Desde esta perspectiva, un análisis conceptual implica necesariamente dos aportes: (i) una aproximación al análisis semántico de un caso particular (que explora significados y, por lo tanto, es referencia teórica); (ii) una aproximación al análisis de la sintaxis argumentativa de un caso particular (que explora la estructura y, por lo tanto, implicaría una referencia epistemológica). En este momento, no abordaré (ii), excepto cuando sea relevante para (i). 
Como vimos anteriormente, la cuestión terminológica está presente en los marcos teóricos que fundamentan la corriente principal de estudios sobre equidad, desigualdad y salud, desde Rawls y Sen a los economistas de la salud.

Al considerar el segundo principio de justicia, como aplicación del axioma que designa la "concepción general de justicia como justeza" (general conception of justice as fairness), Rawls demarca conceptualmente la justicia (justice) como una categoría institucionalizada de justeza (fairness) $)^{(17)}$. Por otro lado, no distingue con claridad y rigor suficientes equidad (equity) de igualdad (equality), incluso utilizando consistentemente el término desigualdades (siempre inequalities, en la obra rawlsiana, y nunca inequities) como base nominal para justificar ese principio de justicia. Finalmente, al establecer el "principio de diferencia", Rawls utiliza el término difference para designar soluciones normativas que toman la distribución compensatoria de bienes y recursos como socialmente correcta y justa ${ }^{(17)}$.

Como vimos, Sen dialoga (y pretende superar) la teoría rawlsiana. Al proponer su débil axioma de equidad, emplea los términos equity e inequality como referentes de la justicia redistributiva. En su obra específica sobre el tema ${ }^{(22,24,25)}$, Sen raramente emplea el término inequity como antónimo simétrico de equity, excepto en un intrigante fragmento: "The inequity of income inequality in leading to unequal utilities (reflecting the loss of social welfare from inequality of individual utilities associated with inequality of incomes)"(24). En este fragmento, inequity se define como "pérdida del bienestar social" y se constituye como una propiedad de "income inequality". Sen tampoco parece distinguir entidades semánticas correlacionadas con el concepto de desigualdad (inequality), tomando de modo indistinto las nociones de "diferencia" (difference), "diversidad" (diversity) y pluralidad (plurality) como equivalentes de la variación individual o contraste entre colectivos humanos. En su análisis de la equidad en el espacio económico, frente a otras dimensiones del bienestar social, recorre los términos similitud y diversidad ${ }^{(23)}$.
En diversos puntos de On economic inequality ${ }^{(22)}$ es posible notar que Sen emplea significantes correlativos al concepto de desigualdades, sin mostrar cierta preocupación por el rigor, la precisión y la consistencia terminológica. Veamos algunos ejemplos:

El hecho básico de la diversidad humana [...] diferimos no solo en nuestra riqueza heredada, sino también en nuestras características personales [...], nuestra diversidad personal. Además de la variación puramente individual (por ejemplo, habilidades, predisposiciones, diferencias físicas), existen también contrastes sistemáticos entre grupos. [...] La pluralidad de variables focales puede hacer una gran diferencia precisamente a causa de la diversidad de los seres humanos. [...] Tales diversidades [son] diversidades interpersonales. (Cursivas añadidas)

Específicamente en lo que se refiere a la bibliografía sobre las relaciones entre desigualdades y salud, es posible verificar la misma falta de precisión y rigor entre los herederos intelectuales de Rawls-Sen. Tomemos como elocuente ilustración de esa problemática terminológica la sentencia de apertura del capítulo central de una influyente compilación de textos sobre el tema que, en el pasaje al siglo XXI, pretendió delimitar la discusión teórica de las desigualdades en salud ${ }^{(12)}$

Estos importantes hallazgos de la bibliografía sobre determinantes sociales han tenido una gran influencia $-y$ continuarán siendo críticos- para nuestra comprensión de las iniquidades en salud [A]. Hay un interés creciente por investigar de forma más explícita las cuestiones complejas sobre la justeza de disparidades en salud $[\mathrm{B}]$ - Al pensar sobre cómo distinguir las variaciones en salud [C] de iniquidades en salud [A]. Hacer tal distinción en parte implica considerar el factor que causa estos diferenciales en salud [D]. [...] Un análisis preciso de los orígenes sociales de los diferenciales en salud [D], puede revelar puntos de entrada en 
la política para la acción eficaz para cambiar las inequidades [E]. Este capítulo presenta tal estructura para pensar sobre la base social de las desigualdades en salud [F]. [Traducción de: These important findings from the social determinants literature have greatly influenced - and will continue to be critical to - our understanding of inequities in health $[\mathrm{A}]$. There is now increasing interest in a more explicit investigation of the complex issues about the fairness of disparities in health $[\mathrm{B}]$ - thinking about how to differentiate variations in health [C] from inequities in health [A]. Part of making this distinction entails looking at the factor that cause these differentials in health [D]. [...] An accurate analysis of the social origins of differentials in health [D], therefore, may reveal policy entry points for effective action to redress inequities [E]. This chapter presents one such framework for thinking about the social basis of inequalities in health [F].

Veamos en detalle la estructura del argumento lógico de este fragmento tan ilustrativo. En principio, con ayuda de los marcadores introducidos en el cuerpo textual (A, B, ... F), es posible delinear una propuesta de glosario:
A: iniquidades [inequities] en salud
B: disparidades [disparities] en salud
C: variaciones [variations] en salud
D: diferenciales [differentials] en salud
E: inequidades [inequities] en salud
F: desigualdades [inequalities] en salud

Para un análisis de consistencia de las relaciones lógicas postuladas en el argumento, podemos formalizarlo como sistema de proposiciones:

1. A es distinguible de $\mathrm{C}$, por eso se recomienda "pensar cómo diferenciar" uno del otro; en consecuencia, $A \neq C$;

2. $B$ parece ser más general que $A$ y $C$, pero el texto es ambiguo, dado que $\mathrm{D}$ no implica necesariamente un término de un nivel mayor del mismo orden de $\mathrm{A}$ y $\mathrm{C}$; así, tal vez $B \subset(A, C)$;

3. A y $C$ son subtipos de $D$;

4. Si $D \subset(A, C)$, consecuentemente, tal vez $\mathrm{B}=\mathrm{D}$. Así, el conocimiento de los orígenes de $\mathrm{D}$ puede ayudar a cambiar $\mathrm{E}$;

5. Entonces, $\mathrm{D}=>\mathrm{E}$;

6. A es un caso restringido de $E$, pues $A$ es " $E$ en la salud";

7. Por analogía, $\mathrm{D}=\mathrm{F}$ y tal vez $\mathrm{B}=\mathrm{D}=\mathrm{F}$, pero esto es inconsistente con aceptar que $E$ es un subconjunto de $F$.

Un breve análisis lógico-semántico de la muestra textual evaluada, incluso de escasa extensión, revela importantes problemas, tales como redundancia, inconsistencia, imprecisión y ambigüedad. Este fragmento, ilustrativo de otros ejemplos, es útil para revelar una gran riqueza semántica, tal como lo demuestra la serie de significantes correspondientes a las desigualdades. Por otro lado, tal amplitud y diversidad semántica puede significar simplemente confusión conceptual, indicativa de la problemática terminológica. La conclusión inmediata y general es que prácticamente todos los estudios de la corriente teórica aquí analizada presentan importantes inconsistencias terminológicas y conceptuales.

Como vimos, influenciadas por las proposiciones de Rawls y Sen, las teorías de justicia que predominan en la bibliografía socioepidemiológica y en abordajes economicistas sobre desigualdades en salud operan a partir de la distinción entre igualdad y equidad. En la medida en que equidad implica un componente estructural de la matriz de valores culturales de la sociedad, hay una evidente equivalencia entre los conceptos de equidad y justicia y, por lo tanto, entre la falta de equidad y la noción de injusticia. A pesar de la insistente referencia a nociones positivas de justicia, justeza y elección social, la problematización teórica y metodológica de los gradientes sociales en salud prioriza la negatividad, operando conceptos de desigualdad y diferencia en lugar de igualdad y equidad. En suma, se estudian las desigualdades y las enfermedades en vez de la equidad en salud. En ese tipo de abordajes, al priorizar los 
términos de injusticia y enfermedad, tanto la justicia como la salud se sustentan en modos de negación. Tal patrón resulta simétrico y consistente respecto a la definición predominante de la salud como ausencia de enfermedad en el campo de la investigación en salud, tanto individual como colectiva ${ }^{(32)}$.

\section{DESIGUALDADES EN SALUD: PROPUESTA DE ACLARACIÓN SEMÁNTICA}

Además de la confusión terminológica, la prolífica bibliografía sobre determinantes sociales de la salud padece de pobreza teórica, en la medida en que raramente explicitan sus fundamentos teórico-conceptuales cruciales para la comprensión del significado de los conceptos relacionados con las desigualdades en los procesos de salud-enfermedad-cuidado en poblaciones ${ }^{(12,40,51,53,54)}$. En contraste, desde una perspectiva asumidamente vinculada a las epistemologías del sur, la importante contribución de Jaime Breilh epidemiólogo ecuatoriano reconocido como uno de los más importantes teóricos del pensamiento crítico latinoamericano- analiza el significado de las variaciones y las desigualdades en la salud y en la enfermedad, frente a las dimensiones individuales y colectivas, desde un abordaje crítico, riguroso, consistente, y situado históricamente con relación a agendas políticas transformadoras ${ }^{(55,56,57,58)}$.

Breilh $^{(55,56)}$ parte del concepto clave diversidad, que correspondería a cualquier variación en características o atributos de una población dada (género, nacionalidad, etnia, generación, cultura etc.). Desigualdad, para este autor, correspondería a evidencias empíricamente observables de la diversidad. Tales conceptos pueden adquirir un sentido positivo en sociedades en las que predominan relaciones solidarias y de cooperación entre géneros y grupos étnicos. Dentro de este referencial, Breilh adopta el neologismo inequidad -que había sido propuesto por Castellanos como traducción directa del término inequity- definiéndolo como categoría analítica opuesta a la equidad, noción que marcaría la solución neoliberal del problema de la distribución de bienes en la sociedad. Para Breilh, la inequidad constituye el lado negativo de la diversidad, manifestándose como vehículo y vector de explotación, subordinación y opresión. El término iniquidad, a su vez, sería sinónimo de injusticia. Las diferencias constituirían la expresión de la diversidad en sociedades solidarias, o de la inequidad entre individuos, en sociedades en las que exista concentración de poder ${ }^{(55,56)}$.

La distinción entre inequidad e iniquidad propuesta por Breilh pretende demarcar la dimensión compleja de la determinación social de la salud ${ }^{(56,57,58)}$, en la medida en que postula que la distribución desigual de bienes en una sociedad no tendría solo una raíz política directamente referida a la justicia social (iniquidad), sino que estaría sobredeterminada estructuralmente (inequidad). Sin embargo, los elementos estructurales y jurídico-políticos de las desigualdades, tomados casi como dispositivos diagnósticos, aún no abarcan plenamente la complejidad de cuestiones vinculadas a la superación de las alienaciones sociales. De hecho, es preciso considerar los elementos simbólicos referidos a la ética política y a la moral social, expresados en los sentimientos de indignación y vergüenza que, colectivamente organizados, constituyen el motor de los procesos de transformación radical de las sociedades para la diversidad emancipadora, sustentable y solidaria $^{(56)}$.

Antes de proseguir, cabe una consideración preliminar, esencial para la propuesta de articulación semántica de los conceptos de equidad en salud, objeto de esta sección. Propongo incorporar al debate sobre desigualdades en salud el concepto de "distinción", tal como lo define el sociólogo francés Pierre Bourdieu (1930-2002), en una de sus obras más reconocidas, titulada justamente La distinction ${ }^{(28)}$. Para él, a partir de la interacción entre diferencias, semejanzas, disparidades, igualdades y desigualdades individuales y homogeneidad y diversidad colectivas, en el proceso cotidiano de construcción de subjetividades e identidades, los 
sujetos y las familias buscan diferenciarse de otros miembros de los grupos sociales y comunitarios a los cuales pertenecen. Para caracterizar ese movimiento de diferenciación, Bourdieu propone el concepto de "estrategias de distinción", refiriéndose a prácticas culturales vinculadas al estilo y al gusto, entre muchas otras formas de estrategias de reproducción. Consideradas como una parte importante de los sistemas de reconversión de las diversas especies de capital (económico, cultural, social, etc.), Bourdieu ${ }^{(28)}$ define las estrategias de reproducción como el "conjunto de prácticas fenomenalmente muy diferentes, por medio de las cuales los individuos y las familias tienden, de manera consciente o inconsciente, a conservar o a aumentar su patrimonio y, correlativamente, a mantener o mejorar su posición en la estructura de las relaciones de clase". Afirma, además, que tales prácticas o estrategias de "disposición estética", "principio de la transformación permanente de los gustos, permiten a las fracciones dominadas, económicamente menos dotadas y por tanto consagradas casi exclusivamente a la apropiación simbólica, asegurarse en cada momento sus posesiones exclusivas". Nótese que aquí el término "estrategia" se emplea en un sentido distinto al del sentido común y al de la teoría convencional de la acción racional, de gran influencia en Rawls, Sen y sus discípulos.

A partir de la proposición de Bourdieu, por lo tanto, es posible incorporar a la discusión teórica de la salud, diferencias y diversidades de tipo cultural que pasaron a ser reconocidas a través de un concepto de sentido pleno designado como "distinción" que, al situarse de forma predominante (pero no exclusivamente) en el plano simbólico, había sido ignorado o aparecía típicamente como mero residuo de la vida social de los seres humanos como, por ejemplo, gustos, estilos de vida, conductas de riesgo e idiosincrasias de base étnico-cultural ${ }^{(59)}$. Eso implica considerar que, en las series semánticas tomadas como fundamento lingüístico de los conceptos, existe un componente etnológico esencial para comprender la dinámica de las desigualdades, inequidades e iniquidades en salud en la sociedad.
De acuerdo con Braveman ${ }^{(49,50)}$, consideremos axiomáticamente el concepto de "disparidad" como forma general de variaciones o diferencias individuales que cobran expresión colectiva en las sociedades humanas como variedad o diversidad. Las formas particulares del significante "variación" y su derivado "variedad" comprenden justamente los objetos conceptuales del presente ensayo. Algunos de estos conceptos pueden ser articulados en una cadena significante de pares o díadas, por ejemplo: similitud/diferencia; igualdad/ desigualdad; equidad/inequidad. Otras manifestaciones de las disparidades asumen definiciones tan peculiares que se sustentan en positividades propias, y conforman una cadena significante monádica compuesta por los conceptos diversidad-distinción-iniquidad. La Tabla 1 presenta los principales significantes pertinentes a esta temática, indicando términos equivalentes en los principales idiomas ${ }^{(53)}$.

Como ejercicio argumentativo, articulemos dos series semánticas, seleccionando sus respectivos significantes claves. La variación natural o genética -que se expresa en diferencias individuales provenientes de la interacción entre procesos sociales y biológicos- genera diversidad en espacios colectivos sociales y desigualdades en poblaciones humanas. Por otro lado, las relaciones sociales de dominación, los procesos políticos perversos y las políticas de gobierno promueven desigualdades relacionadas con los ingresos, la educación y el origen social, es decir, inequidades concernientes a la injusticia social estructuralmente vinculada al modo de producción capitalista. Algunas de esas desigualdades, además de injustas, son inicuas $y$, por lo tanto, moralmente inaceptables, dado que constituyen iniquidades que generan indignación y, potencialmente, compromiso personal y social. En paralelo, en los planos simbólico-culturales, al construir identidades sociales fundadas en la interacción entre diferencias individuales y patrones colectivos, la mayoría de las veces a través de mecanismos no conscientes, en el plano del habitus, los seres humanos afirman su distinción de otros como miembros de segmentos, grupos y clases sociales ${ }^{(59)}$. 
Tabla 1. Equivalencia semántica de términos correlativos al concepto de "desigualdad" en idiomas seleccionados.

\begin{tabular}{cccc}
\hline Portugués & Inglés & Español & Francés \\
\hline Variação & Variation & Variación & Variation \\
\hline Variância & Variance & Varianza & Variance \\
\hline Invariância & Invariance & Invariancia & Invariance \\
\hline Variedade & Variety & Variedad & Variété \\
\hline Diversidade & Diversity & Diversidad & Diversité \\
\hline Unidade & Unity & Unidad & Unité \\
\hline Diferença & Difference & Diferencia & Différence \\
\hline Semelhança & Similarity & Similitud & Similitude \\
\hline Disparidade & Disparity & Disparidad & Disparité \\
\hline Paridade & Parity & Paridad & Parité \\
\hline Desigualdade & Inequality & Desigualdad & Inégalité \\
\hline Igualdade & Equality & Igualdad & Égalité \\
\hline Distinção & Distinction & Distinción & Distinction \\
\hline Vulgaridade & Commonness & Vulgaridad & Vulgarité \\
\hline Heterogeneidade & Heterogeneity & Heterogeneidad & Heterogeneité \\
\hline Homogeneidade & Homogeneity & Homogeneidad & Homogénéité \\
\hline Pluralidade & Plurality & Pluralidad & Pluralité \\
\hline Singularidade & Singularity & Singularidad & Singularité \\
\hline Equidade & Equity & Equidad & Équité \\
\hline Iniquidade & -- & Iniquidad & Iniquité \\
\hline Inequidade & Inequity & Inequidad & -- \\
\hline Fuente: Elaboración propia. & & & \\
\hline & & & \\
\hline & & & \\
\hline
\end{tabular}

Ampliando y revisando un glosario pertinente a esa cadena argumentativa, propuesto a partir de analizar la problemática teórica de la determinación social de la salud mencionada en la introducción ${ }^{(1)}$, podemos plantear las siguientes definiciones:

- Diversidad: variación de las características (género, afiliación étnica, matriz cultural, nacionalidad, generación) de los miembros de una colectividad o población. Así, mientras biodiversidad es la propiedad de un territorio dado, etnodiversidad puede ser atributo de una nación y, epistemodiversidad, de un contexto histórico dado. Sin embargo, por definición y respetando las estructuras lingüísticas pertinentes, semánticamente no tiene sentido atribuir diversidad a sujetos individuales.
- Diferencia: expresión individual de efectos de la diversidad y/o desigualdad en sujetos considerados de forma aislada. Más allá de que surjan frecuentemente diferencias biológicas como variaciones naturales o genéticas, se manifiestan mediante complejas relaciones entre procesos sociales y biológicos en los sujetos individuales. Equivaldría, grosso modo, al concepto de endowment de Rawls. Las diferencias pueden determinar efectos en indicadores de ocurrencia acumulativa en colectividades, como medidas epidemiológicas de riesgo.

- Distinción: atributo relacional, interpersonal, que no forma parte de diferencias naturales ni se condice con las desigualdades sociales resultantes de políticas desiguales. La búsqueda de la distinción es una práctica cultural cotidiana de los agentes sociales, organizados colectivamente o no en la 
producción social y simbólica de sentidos, mediante la expresión, la creación y el cultivo de gustos y estilos productores de identidades.

- Desigualdad: diferenciación dimensional o variación cuantitativa en colectividades o poblaciones. Puede expresarse a través de indicadores demográficos o epidemiológicos (en el campo de la salud), como "evidencia empírica de diferencias". En este caso, puede constituir una capability, en el sentido de Sen, sin que necesariamente se corresponda con las consecuencias de injusticias, como es el caso de la noción de salud social como efecto de múltiples determinaciones.

- Inequidad: denota disparidades evitables e injustas, expresa desigualdades innecesarias e indeseables desde el punto de vista político, en poblaciones humanas y sus colectivos. Se trata de un neologismo de inequity, en una acepción convergente (pero no equivalente) al sentido propuesto por Breilh ${ }^{(55)}$. Aquí significa lo opuesto a equidad, o sea, ausencia de justicia en lo referente a políticas distributivas sociales y de salud.

- Iniquidad: corresponde a inequidades que, además de evitables e injustas, son indignas, vergonzosas, que son el resultado de la opresión social (segregación, discriminación, persecución) en presencia de diversidad, desigualdad, diferencia o distinción. Se trata de una ausencia extrema de equidad, derivada del efecto de estructuras sociales perversas y del ejercicio de políticas inicuas, generadores de desigualdades sociales ética, moral y políticamente inaceptables.

En suma, y retomando la idea de Sen de cuasiordenamiento en espacios o dimensiones simultáneas, se consideran los fenómenos de disparidad social en planos o campos distintos, en los que el concepto de "diversidad" remite primordialmente a la especie; "diferencia", al plano individual; "desigualdad", a la esfera económico-social; "inequidad", al campo de la justicia; "iniquidad", al campo político; y "distinción", al simbólico.

Apliquemos esta serie semántica a la cuestión general de las disparidades en salud.
Primero, las desigualdades (variación cuantitativa en colectividades o poblaciones) pueden ser expresadas por indicadores demográficos o epidemiológicos (en el campo de la salud) como "evidencia empírica de diferencias", en lo que se refiere al estado de salud y al acceso o uso de recursos asistenciales. Segundo, las desigualdades en salud, determinadas por diferencias relacionadas con los ingresos, la educación, la clase social y otros factores, en la medida en que adquieren sentido en el campo político como resultantes de conflictos vinculados a la distribución de la riqueza en la sociedad, deben ser consideradas como producto de la injusticia social y, por lo tanto, como inequidades en salud. Tercero, las inequidades en salud que, además de evitables e injustas, resultan avergonzantes, inmorales, indignas, agreden nuestros principios éticos y valores políticos y despiertan sentimientos de aversión y disgusto, conforman iniquidades en salud.

Sin duda, las dimensiones políticas de las desigualdades en salud constituyen una cuestión fundamental, incluso para las propuestas teóricas oriundas del liberalismo. En una cuidadosa revisión de la primera ola de análisis que generó la teoría Rawls-Sen-Whitehead, Spinelli ${ }^{(40)}$ comenta que "la lógica del bienestar deja de estar relacionada de manera unívoca con la incorporación de bienes, para centrarse en la búsqueda de condiciones que permitan a los sujetos individuales y/o colectivos potenciar sus capacidades de realización". Como avance conceptual, propone superar tanto la perspectiva individualista y fragmentaria de la salud como efecto de capabilities, como la noción solo técnica y operacional de evitabilidad, en lo que se refiere a las inequidades en salud. Dentro de esa perspectiva crítica, distinguir inequidad de iniquidad no constituye un mero ejercicio semántico. Significa introducir, en el proceso de teorización, presuntamente neutro e impersonal, elementos de indignación personal y moral.

Por lo tanto, tomar como referencia solo la cuestión de la equidad (y de su opuesto, la inequidad) en la esfera nominal de la justicia, como si la inequidad se determinara en el campo de la voluntad, como mero problema 
de libre elección de sujetos, por supuesto, libres, parece insuficiente respecto del tema de la dignidad humana ${ }^{(60,61)}$. La protección de los derechos básicos de una persona que cometió un crimen o la garantía de las prerrogativas jurídicas de una persona sospechada de corrupción es ciertamente una cuestión de equidad y, su supresión o negación, una inequidad, puesto que evoca el fundamento democrático de justicia igual para todos. Sin embargo, la mortalidad infantil por desnutrición en un país exportador de alimentos, los episodios de agresión homofóbica o de femicidio, la negación de cuidado urgente por razones mercantilistas o una mutilación producto de violencia racial o de intolerancia religiosa conforman elocuentes ejemplos de iniquidad en salud.

\section{FUNDAMENTOS TEÓRICOS SOBRE DESIGUALDADES EN SALUD}

A partir de esa propuesta de solución de la problemática terminológica, podemos señalar algunas cuestiones epistemológicas, conceptuales y metodológicas capaces de alimentar un debate sobre modelos teóricos que, en este momento de crisis y transiciones, requiere ser ampliado y profundizado. Entre muchos aspectos teóricos pertinentes, nos preguntamos ¿cuáles son los fundamentos de la desigualdad, la inequidad y la iniquidad en salud? ¿Cómo abordar, de un modo conceptualmente consistente y metodológicamente riguroso, tales cuestiones? ¿Cómo operan la opresión y la injusticia en la promoción y persistencia de las iniquidades en salud en el plano concreto del cotidiano social?

Un primer paso consiste en intentar comprender el papel de las desigualdades sociales en la producción de enfermedad, morbilidad y mortalidad, tanto como salud, calidad y extensión de la vida humana. En este sentido, es imperativo abordar la cuestión de Sen - “¿desigualdad de qué?" (estados, procesos, eventos)-, lo que implica, ante todo, acción, forma, dinámica y actuación de las fuerzas políticas y de las jerarquías sociales. Un segundo paso será, ciertamente, la búsqueda de alternativas en el plano de la articulación teórico-metodológica, a fin de explorar y evaluar en cuál nivel de abstracción operan mejor los conceptos de desigualdades en salud y sus conceptos conexos ${ }^{(40,44,53,57)}$.

La pregunta de base sería: ¿dónde (en el sentido de espacio social y político) actúan los determinantes sociales de la salud? En primer lugar, en la dimensión poblacional, que abarca los niveles individual y colectivo, en los que se destacan las amplitudes territoriales (municipio, estado, país). En segundo lugar, en la dimensión social, micro (familia, grupo de pares, etc.) y macrosocial (estratos, clase social, etc.). En tercer lugar, en la dimensión simbólico-cultural, que opera recortes étnico-raciales (subculturas, grupos étnicos, etc.) y de identidad de género.

Metodológicamente, esa cuestión requiere el desarrollo de indicadores de segundo nivel para evaluar correlaciones con heterogeneidades o diferencias intragrupales. En el plano específico de la construcción metodológica, ¿qué orden de determinantes sería pertinente para comprender la génesis y los efectos de las iniquidades en salud? Con antelación, es necesario establecer las fuentes y los orígenes de las desigualdades de modo distinto, pero complementario, a la aproximación necesaria a los temas de la naturaleza y los componentes de las desigualdades sociales en salud, desde el punto de vista de su mensuración ${ }^{(45,49,62)}$. Primero, las fuentes de iniquidad en salud, desde la diferencia, serían generación, género, herencia familiar y etnicidad. En segundo lugar, desde la distinción, serían religión, comunidad, comportamiento y habitus. En tercer lugar, desde el ángulo de la desigualdad, serían ocupación, educación, ingresos, riqueza y poder.

Dentro de este esquema, se pueden mencionar algunos componentes de la cadena determinante de las desigualdades en salud: disponibilidad de recursos sociales (ingresos, poder, etc.); diversidad de modos de vida; desigualdades en salud; acceso diferenciado; y segregación del sistema de cuidado a la salud. En lo concerniente a los dos últimos ítems citados, una ampliación pertinente, 
aunque parcial, del alcance de ese campo de indagaciones nos llevaría a hablar no solo de enfermedad, sufrimiento y muerte, sino también de vulnerabilidad y riesgo ${ }^{(63,64)}$. El referencial de las desigualdades sociales en salud debe incorporar la idea de vulnerabilidad social como uno de sus focos, agregando categorías relacionadas, definidas de acuerdo con el plano de realidad considerado, como las nociones de fragilidad, vulnerabilidad, susceptibilidad y debilidad (32).

En tercer lugar, como segmentación de ese plano de articulación, es imprescindible investigar los efectos de las desigualdades sociales en el modo de vida, en el estilo de vida y en la calidad de vida relativa a la salud de los sujetos, mediante procesos de producción social de salud-enfermedad-cuidado. La demanda conceptual de ese desafiante programa de investigación implica la construcción y validación de modelos explicativos de los procesos históricos y sociales que definan las desigualdades como objeto de conocimiento, y que tengan como referencia las teorías críticas de equidad y justicia en contextos democráticos como, por ejemplo, las obras de Habermas ${ }^{(16)}$ y de Boaventura de Sousa Santos $^{(30,31,61)}$. En el plano específico, podemos recorrer la teorías de la sociedad y de la política que abordan la regulación jurídica de las prácticas de los sujetos concretos en el espacio social, en especial, la contribución de la filósofa húngara Agnes Heller(60).

En Além da justiça ${ }^{(60)}$, un magistral análisis de las formas jurídicas estructurantes de la sociedad occidental contemporánea, Heller hace una crítica directa a la teoría de la justicia de Rawls y sus bifurcaciones. El foco de esa crítica está claramente establecido: "determinar si la realización del valor universal de 'igualdad en las oportunidades de la vida' presupone igualdad distributiva o alguna forma de desigualdad distributiva"(60). Para esta autora, la cuestión de los orígenes de la equidad y de la desigualdad en la estructura actual de dominación, identificada en conceptos como propiedad, capital, lucro y trabajo, constituye un punto ciego de la visión liberal, dado que "Rawls y sus seguidores no argumentan sobre los aspectos empíricos del Estado de bienestar democrático moderno"(60). Por eso, concluye Heller, que el "principio de diferencia" de Rawls no tiene ningún sustento, incluso "en el contexto de un Estado de bienestar radical"(60).

Heller derriba la tesis de que, en la sociedad contemporánea (occidental), el mérito corresponde al talento, lo que justificaría moralmente mayor lucro, ingresos y riqueza a una elite económica, intelectual y política, al afirmar que ${ }^{(60)}$

La tesis inicial de este argumento es completamente falsa. [...] ¿Podemos creer seriamente que, incluso en circunstancias imaginarias, a las personas se les paga de acuerdo con sus talentos generales? Es sabiduría común que cada persona nace con incontables dones. Cuáles de estos se tornan "talentos", depende tanto de la "lotería social" como de la "genética". Somos lanzados en un mundo particular por accidente, y nos tornamos lo que somos al lidiar tanto con aprioris "sociales" como "genéticos" de nuestra existencia. [Cursivas del original]

Si buscamos extraer de su argumentación una propuesta concreta, podríamos decir que Heller propone un "concepto ético-político incompleto de justicia", capaz de establecer "una base normativa común para diferentes modos de vida"(60). Sin embargo, esa base normativa requeriría asumir un carácter más ético-político y menos moral, en la medida en que las normas morales, por definición, son opresivas, pues "reprimen instintos y deseos; [...] despojan personas de su autonomía; son agentes de dominación (política, económica, sexual)"(60). En su crítica, Heller deconstruye elementos centrales de las justificaciones de modelos de redistribución de ingresos, en general, políticas compensatorias estatales de promoción de equidad redistributiva, mediante el acceso a servicios públicos que garantizan los derechos humanos individuales (salud, educación etc.), como una forma de atenuar las desigualdades económicas y sociales, generadas por las diferencias (inevitables, dirían Rawls, Sen y otros) de mérito y talento, 
en el contexto de un modo de producción que se viabiliza justamente por ser explotador, concentrador, injusto y excluyente.

En síntesis, se trata de la necesidad de comprender las relaciones entre "modo de vida" y salud ${ }^{(40,52)}$, aprovechando concepciones no dimensionales como, por ejemplo, la idea de iniquidad y el concepto de habitus de Bourdieu ${ }^{(59)}$. En términos de Mario Testa ${ }^{(65)}$, esto significa sumergirse -desde un punto de vista etnográfico- en la cotidianidad, para focalizar en las prácticas de la vida cotidiana $y$, dentro de ellas, el efecto local de la distribución desigual de los determinantes sociales de la salud y su impacto sobre procesos generales de determinación de la salud-enfermedad-cuidado.

\section{MODELO SINTÉTICO DE DESIGUALDADES EN SALUD}

En 2005, la Organización Mundial de la Salud creó una comisión independiente de expertos, presidida por Sir Michael Marmot ${ }^{(6,667)}$, con el objetivo de sistematizar el conocimiento científico sobre "determinantes sociales: pobreza, desigualdad y las causas de las causas", en términos de morbilidad y mortalidad. El informe final de la comisión se dirigía a los gobiernos, las agencias internacionales y las ONG, con la ambición de desencadenar una acción global para promover criterios de salud social, a fin de intervenir en los determinantes de las desigualdades en salud ${ }^{(67)}$. Se presentó un modelo explicativo que diferencia dos tipos de determinantes sociales de la salud: determinantes estructurales y determinantes intermedios. Los determinantes estructurales se refieren a la estratificación social definida por el estatus socioeconómico individual, que produce riesgos diferenciales a la salud de acuerdo con su origen social, posición en la jerarquía del poder y del acceso a los recursos económicos. Los determinantes sociales intermedios incluyen las condiciones y los factores que comprometen la salud, clasificados en bloques: circunstancias materiales, circunstancias psicosociales, estilo de vida, y acceso a los sistemas de salud.
Las circunstancias materiales están vinculadas al ambiente físico (vivienda, consumo, trabajo, vecindario), mientras las circunstancias psicosociales se relacionan con experiencias individuales y situaciones estresantes, que incluyen la falta de apoyo social. El estilo de vida comprende variables comportamentales, como nutrición, actividad física, tabaquismo y abuso de alcohol. Además de estos, el acceso a los sistemas públicos de salud es reconocido como un determinante social de salud importante, en el sentido de que puede reducir riesgos y vulnerabilidades y garantizar cuidados, por lo que mejora los pronósticos y la recuperación de $\operatorname{casos}^{(67)}$.

Aunque el informe reconozca que "la injusticia social está matando personas a gran escala" y reafirme la necesidad de intervenir en todos los determinantes de todas las áreas, "tanto para eliminar las desigualdades estructurales como para alcanzar un bienestar más inmediato" ${ }^{\prime(67)}$, la insistencia en tratar determinantes sociales de la salud como entidades separadas en compartimentos estancos tuvo dos consecuencias. Por un lado, los principios, los valores y las recomendaciones de esa iniciativa se incorporaron de inmediato a las políticas y los programas sociales en varios Estados de bienestar social como, por ejemplo, Canadá y Australia ${ }^{(68)}$. Por otro lado, en esa estrategia, las desigualdades sociales se incluyeron como un único componente adicionado a una extensa lista de determinantes sociales de la salud (junto con educación, género, desempleo, exclusión social, condiciones de trabajo, desarrollo infantil, inseguridad alimentaria, vivienda, seguridad social, raza, etnia y otros), omitiendo los elementos estructurales y las raíces políticas de los procesos sociales cruciales para la capacidad heurística de las teorías de la producción social de enfermedades o de determinación social de la salud, más allá de la referencia meramente retórica a las "causas de las causas de las causas" de las desigualdades en salud ${ }^{(69,70,71,72,73)}$.

El análisis de los principios de equidad, en sus diversas vertientes, lleva a cuestionar el discurso tecnocrático (economicista) con relación al tema de las desigualdades en salud, como uno más de los determinantes 
sociales de la salud. Eso se basa en la constatación, casi trivial, de que la salud no se puede producir, almacenar, invertir, redistribuir linealmente del mismo modo que los ingresos o la riqueza. De hecho, en el campo de la salud hay serios impedimentos éticos y políticos para las intervenciones redistributivas. Las desigualdades en salud no pueden ser objeto de políticas distributivas focales pues, desde una perspectiva ética rigurosa, la salud no puede ser parte de las "Robin Hood policies"(74), recomendables para la redistribución de riquezas e ingresos mediante recaudación compulsiva (por vía tributaria) de recursos financieros de los más ricos y puestos a disposición de los más pobres por medio de subsidios, exenciones, prestación de servicios gratuitos o políticas públicas compensatorias.

Por lo tanto, cabe retomar el cuestionamiento de Krieger ${ }^{(13)}$, destacado en la introducción de este ensayo, que refería a la persistencia de lagunas, omisiones y sesgos en las teorías sobre determinantes de la salud en el discurso dominante que es representativo de las epistemologías del norte global, particularmente en el tema de las desigualdades sociales en salud. La propia Nancy Krieger tomó la iniciativa de organizar en la Universidad de Harvard, en $2010^{(69)}$, un workshop con investigadores estadounidenses y latinoamericanos interesados en el asunto, cuyo foco eran las teorías de determinación social de la salud, reconociendo así, como otros autores ${ }^{(13,46,51,73,75,76)}$, el avance de la reflexión teórica sobre ese tema en la epidemiología social de América Latina. De hecho, Jaime Breilh ${ }^{(55,56,57,58)}$, Cristina Laurell ${ }^{(77,78)}$, Ricardo Bruno Gonçalves ${ }^{(79)}$, Pedro Luis Castellanos ${ }^{(80,81)}$ y otros autores latinoamericanos desarrollaron modelos teóricos de gran potencial heurístico, tomando las desigualdades en salud como un objeto de conocimiento capaz de explicar las complejas relaciones que producen pobreza o privaciones, desigualdades e iniquidades en salud. En general, esas teorías abordan las raíces de las desigualdades sociales y producen modelos de gran utilidad para la investigación social en salud, que operan en un nivel más alto de abstracción ${ }^{(52,53,72,73)}$. Por esa razón, reducen su poder explicativo al abordar la realidad concreta, y dejan menos espacio al trabajo metodológico necesario para generar hipótesis más precisas, listas para ser contrastadas empíricamente, mediante una práctica científica rigurosa y competente.

En este sentido, la contribución de Castellanos, en su colaboración con Samaja, nos permite problematizar el tema de las desigualdades sanitarias a nivel pragmático formal, basado en el concepto operativo de "situación de salud"(80,81). Las situaciones de salud en territorios concretos son "expresión de las diferentes condiciones de vida y de trabajo", y necesariamente forman parte del contrato social que, en las sociedades modernas, definen como "responsabilidad del Estado propiciar las respuestas sociales necesarias y posibles, reducir la inequidad en los recursos económicos, las condiciones de vida, el estado de salud y el acceso a sistemas, programas y servicios de salud"(81). Sin embargo, para este autor ${ }^{(81)}$

No toda diferencia en la situación de salud de las poblaciones puede ser considerada una inequidad. Pero toda diferencia o brecha reducible vinculada a diferentes condiciones de vida, constituye una inequidad.

En este programa teórico ${ }^{(80)}$, para modelar el proceso de transformación de las desigualdades sociales en inequidades en salud e introducir más precisión en la construcción conceptual, se debe descomponer la situación de salud -tomada como elemento sistémico- en "estado de salud" y "cuidados de salud". El estado de salud es el resultado de los procesos de transformación de la estructura epidemiológica de una población dada. A su vez, los cuidados de salud son producto de un complejo sistema de respuesta social, que expresa el juego de acciones, servicios y tecnologías involucradas en las prácticas sociales de cuidar, tratar, sanar y curar. Mientras el cuidado de la salud implica un proceso, el estado de salud indica un outcome.

Con base en ese aporte, propongo desarrollar el esquema de construcción conceptual esbozado, con la ayuda de un modelo 


\section{POBREZA $>>>>>>>>>>>>>>>N O N-S A L U D$ DESIGUALDADES SOCIALES $>>>$ INIQUIDADES EN SALUD}

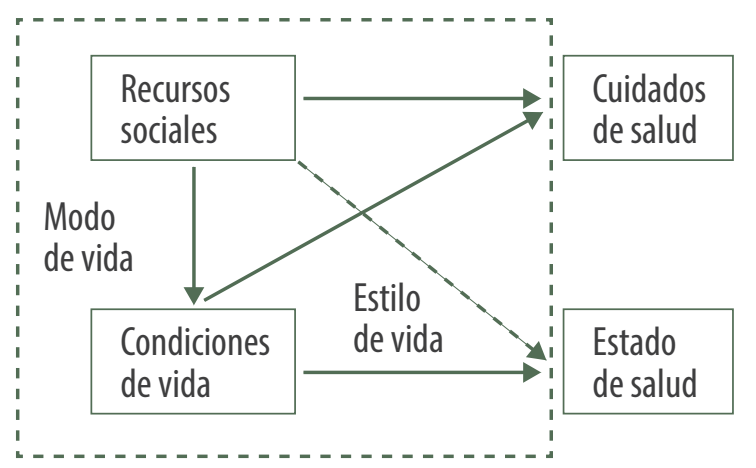

Figura 1. Modelo de articulación de los componentes de las desigualdades en salud.

Fuente: Elaboración propia.

de articulación de los componentes de las desigualdades en salud, de acuerdo con la Figura 1. A lo largo de esta sección, el término "inequidad en salud" se usará para representar carencias o déficit de equidad tanto en los cuidados de salud como en el estado de salud.

Este es un esfuerzo para refinar la hipótesis de investigación epidemiológica planteada por los modelos de determinación social, que convergen en los eslabones entre desigualdad social e inequidad en salud y entre pobreza y estado de enfermedad ${ }^{(52,53,57,69,72)}$. La Figura 1 puede guiar la selección de variables en la investigación empírica sobre el tema. Los recursos sociales (RS) no solo determinan directamente el estado de salud (ES), sino que también su efecto principal se ejerce a través de dos sendas: a) alterando condiciones de vida (CV); b) afectando los cuidados de salud (CS). La Figura 1 puede verse como un esquema general para representar los procesos resultantes del modelo de determinación social de las inequidades en salud, que puede servir para una comprensión más clara de una red tan compleja de conceptos.
Matemáticamente, esa relación puede expresarse, en su versión más sencilla, en el siguiente sistema de ecuaciones:

$$
\begin{aligned}
& \mathrm{ES}=\alpha+\beta_{1}(\mathrm{RS})+\beta_{2}(\mathrm{CV})+\beta_{3}(\mathrm{CS})+\beta_{\mathrm{n}}\left(\mathrm{X}_{\mathrm{n}}\right) \\
& \mathrm{CS}=\alpha+\beta_{1}(\mathrm{RS})+\beta_{2}(\mathrm{CV})+\beta_{\mathrm{n}}\left(\mathrm{X}_{\mathrm{n}}\right) \\
& \mathrm{CV}=\alpha+\beta_{1}(\mathrm{RS})+\beta_{\mathrm{n}}\left(\mathrm{X}_{\mathrm{n}}\right)
\end{aligned}
$$

Como hemos visto, debemos delimitar la diferencia entre inequidad y pobreza ${ }^{(48)}$. La inequidad se refiere a una distribución relativa de recursos y bienes e indica una comparación esencialmente entre aquellos que pueden permitirse demasiados lujos y aqueIlos que obtienen menos recursos sociales. La pobreza es una cuestión de escasez o supresión y significa falta de disponibilidad o acceso a recursos o bienes. Mientras la inequidad puede ser expresada por medidas relativas como proporciones o gradientes, la pobreza es absoluta y se representa como índices o promedios basados en los umbrales en una escala dada, expresada por proporciones $^{(49,62)}$. Esta distinción influye directamente en la definición de indicadores para los propósitos de la investigación. 
Tomemos la Figura 1 como un "modelo de pobreza": la reducción o carencia de recursos sociales ( $\downarrow$ RS) (políticos, económicos, microculturales) es determinante de privaciones en las condiciones de vida ( $\downarrow$ CV), de cuidados de salud precarios ( $\downarrow$ CS) y de un pobre estado de salud ( $\downarrow$ ES). Las condiciones de vida empeoradas promocionan baja efectividad y accesibilidad a los cuidados de salud $(\downarrow C S)$ y producen, en forma directa, condiciones de enfermedad. Los cuidados de salud de pobre-calidad ( $\downarrow$ CS) también influyen negativamente en el estado de salud global $(\downarrow E S)$. Una formalización provisional de estas interacciones puede ser representada por un modelo de función generalizada de privación, como el siguiente:

$$
\text { Modelo 1: IES }=f_{\text {priv }}(\mathrm{CS}+\mathrm{CV}+\mathrm{RS})
$$

Tomemos ahora la Figura 1 como un "modelo de desigualdades". En ese caso, podríamos considerar cada elemento de la figura no como un lugar donde algo está reducido o falta, sino como una situación o un sistema que padece distribución desigual e injusta de recursos, condiciones, servicios y valores. En otras palabras, las desigualdades sociales (debido a la estructura de clase que opera a través de los procesos de reproducción social, como en el modelo de determinación social de Breilh)(56,57), puede llevar a la inequidad en condiciones de vida (vivienda, nutrición, educación, exposiciones comportamentales y medioambientales) y en cuidados de salud (accesibilidad y efectividad).

La inequidad en las condiciones de vida (ICV) también puede producir iniquidad en cuidados de salud (ICS), debido al escaso acceso y baja calidad en la provisión de cuidados de salud para las personas con menos recursos económicos. La ICV puede determinar la inequidad en el estado de salud (IES), por exposiciones y riesgos aumentados debido al fracaso de mecanismos de prevención de enfermedades o protección de la salud. A su vez, la ICS también fracasa en el sistema de provisión de salud, con una capacidad más reducida de tratamiento y recuperación de casos individuales, lo que disminuye el estado de salud de la población. La línea punteada IRS-IES representa una posible senda determinante directa que podría corresponder al fracaso de políticas de promoción de salud y podría ser un efecto residual del sistema de determinación.

En este caso, como supuesto fundamental y siguiendo a $\operatorname{Sen}^{(23)}$, se podría decir que la inequidad en un espacio o nivel causa inequidades e iniquidades en los otros espacios, dimensiones o elementos del sistema social de salud. Por consiguiente, nosotros podemos formalizar un modelo generalizado de función de inequidad, como el siguiente:

$$
\text { Modelo 2: IES }=f_{\text {inq }}(\text { ICS }+ \text { ICV }+ \text { IRS })
$$

Sin embargo, la pobreza y la inequidad están íntimamente entrelazadas y el establecimiento de funciones distintas para cualquier tipo de suspensión e inequidad es solo una estrategia de simplificación analítica. La privación social lleva a la inequidad en las condiciones de vida (CV) y en los cuidados de salud (CS), de tal modo que puede producir pobres condiciones de vida CV y un peor estado de salud (ES). Sin embargo, nuestro enfoque debe centrarse en la inequidad y no en la pobreza. Para derivar estimaciones de un "efecto directo de inequidad" necesitamos excluir tanto los efectos indirectos de inequidad como los efectos directos de privación. Esto implica modelar la siguiente ecuación de los efectos residuales y directos de la inequidad:

$$
\text { Efecto de inequidad }=f_{\text {inq }}-f_{\text {priv }}
$$

El énfasis en la inequidad se justifica, en primer lugar, porque la noción de pobreza no es capaz de generar, en forma aislada, un modelo realmente eficaz para ayudar a entender y transformar la situación de inequidad en salud, a pesar de su uso extendido como un acercamiento pseudoteórico que sigue prevaleciendo en la mayoría de los países. En segundo lugar, porque incluso aceptar que pobreza o privación económica puede vincularse a condiciones de vida alteradas y acceso reducido y precario a cuidados de salud, no significa determinación directa de 
la pobreza sobre la inequidad en condiciones de vida y en la situación de salud en su conjunto. Ciertos contextos precarios de salud se definen, entonces, como un estado de salud que provee indicadores descriptivos por debajo de una línea mínima de salud. De manera equivalente, los cuidados precarios de salud -que expresan una provisión de servicios de salud por debajo de un cierto umbral de cantidad o calidad de atenciónno son equivalentes a inequidad en los cuidados de salud, lo que implica diferencia e injusticia en el acceso y la disponibilidad de los servicios de salud ${ }^{(48)}$.

Además, un enfoque de pobreza o privación inevitablemente reforzaría la ilusión de que, para la salud, al igual que para cualquier necesidad social, la solución sería aumentar los recursos y no una mayor justicia en la distribución de poder y riqueza entre los grupos sociales. Desde esa posición, la salud es un mero bien, sujeto a las reglas de planificación económica, producción y consumo en un mercado imperfecto. Hay que considerar la salud cada vez más como un valor y como un derecho humano, un problema de justicia social y de acción política, y no como un fenómeno biológico natural.

El juego de definiciones y conjeturas (y sus derivaciones) y el modelo presentado pueden verse como un esfuerzo para clarificar la caja negra "configuraciones del riesgo / procesos salud-enfermedad-cuidado" a la que se referían los autores citados $^{(56,57,78,79,80,81)}$. En este sentido, se reconoce como urgente el modelado simple (low-level) para habilitar aplicaciones epidemiológicas directas (y quizás más convencionales) de los marcos teóricos complejos (higher-level) sobre los determinantes de inequidad social e iniquidades en salud, como factores que condicionan la situación de salud y los aparatos institucionales de cuidado ${ }^{(73)}$. En síntesis, hemos asumido el desafío de una construcción conceptual complementaria a otras propuestas, para ensamblar el formidable arsenal metodológico de la epidemiología con su potencial de transformación de la realidad sanitaria, para la producción local de ciencia en el campo de la salud colectiva ${ }^{(46,56,57,62,72,73)}$.

\section{NUEVAS FORMAS DE DESIGUALDAD EN SALUD}

En las teorías del bienestar social ${ }^{(18,23)}$, la economía, la sociedad y el Estado tendrían como objetivo mejorar la vida de los seres humanos. Bajo este referencial, el welfare state idealmente estaría configurado como un dispositivo institucional concebido para la estabilidad política, la seguridad pública, la administración de justicia y la regulación de los mercados, garantizando los derechos civiles, y promoviendo el bien común y la equidad en las sociedades democráticas ${ }^{(16,60)}$. Las desigualdades económicas y sociales serían, al menos como retórica, subproductos indeseables de la crisis e imprevistos del sistema productivo, a ser superadas por el desarrollo económico, social y humano de los países y por la acción mediadora y, al extremo, intervencionista del Estado, mediante políticas públicas promotoras de equidad, que amplíen la garantía de los derechos y focalicen la distribución de los beneficios en los segmentos sociales menos privilegiados ${ }^{(29)}$.

En este enfoque, desde el plano supranacional, para reducir las desigualdades en el desarrollo humano -incluyendo la salud-, y asociadas a determinantes económicos, sociales y políticos, los organismos internacionales recomendaron el establecimiento de metas estratégicas (por ejemplo, los Objetivos de Desarrollo del Milenio de las Naciones Unidas) ${ }^{(82)}$ para orientar programas multilaterales de inversión. En este contexto, las nociones instrumentales como "brechas de salud" (80), "carga global de enfermedad"(83) y "deuda social de la salud"(84) alcanzaron notoriedad en la última década del siglo pasado, con algún grado de convergencia e incluso de articulación con el tema de las inequidades en salud. Mientras haya personas más expuestas que otras a factores de riesgos ambientales, habitacionales, ocupacionales y comportamentales, y por razones económicas, sociales y políticas, tengan menor acceso a recursos sociales de promoción, protección y recuperación de la salud, habrá inequidades y, por lo tanto, brecha (gap) en la situación de salud o carga (burden) desigual de enfermedad. La 
noción de deuda social, sin embargo, merece un análisis más detallado porque se refiere directamente a la cuestión de las iniquidades en salud.

En la teoría del welfare state, desde la corriente Rawls-Sen, la existencia de sujetos que, por razones económicas o políticas no pueden beneficiarse de políticas públicas demandadas por la sociedad y gestionadas por el Estado, denunciaría una deuda social y política pendiente a ser superada o erradicada. En Brasil, esa retórica está presente desde la transición democrática y la Nueva República, como una respuesta tecnocrática a las críticas de que un modelo de desarrollo basado en endeudamiento externo y concentración de ingresos produce pobreza y desigualdades sociales. Para este discurso, la noción de "deuda social" se justifica "en el presupuesto ético de que cada ciudadano debería tener sus necesidades básicas mínimamente garantizadas; [...] en forma similar a la deuda pública, que sería una deuda de la sociedad con ella misma"(85). En realidad, lo que este enfoque denomina "deuda social" se refiere al conjunto de desigualdades estructurales de la sociedad que determina un compromiso histórico, en muchos casos postergado, pero siempre previsto en las garantías de equidad y justicia de los derechos fundamentales de la persona humana. La deuda social sería, por lo tanto, desigualdades sociales que se tornan iniquidades, en el sentido de una forma peculiar entre las inequidades (definidas como evitables, en la lógica redistributiva) reveladas como efectos perversos de una dinámica sociohistórica fundada en explotación, exclusión y opresión.

Solo se puede hablar de deuda social desde esa perspectiva idealizada en la que el Estado y la sociedad son responsables del bienestar de todos los ciudadanos de un país, un utópico o mítico welfare state, en un plano meramente operativo, restringido a objetos específicos. En el campo de la salud, la deuda social o deuda sanitaria( ${ }^{(84)}$ puede referirse tanto a la distribución desigual de riesgos, en el sentido epidemiológico, como al acceso desigual a los sistemas de asistencia a la salud, con programas efectivos, tecnologías eficaces y disponibles, y prácticas de cuidados de salud realizadas con la mayor calidad humana posible, lo que debe ser garantizado como derecho a todos los miembros de una sociedad dada. Desde esta perspectiva, la deuda social de la salud no podría ser renegociada, pues los plazos que cuestan vidas humanas no pueden ser ampliados. Tampoco sería objeto de auditoria, moratoria o denuncia, simplemente porque implica un problema estructural cuya superación implica un compromiso político, social y moral.

Como estrategia analítica para una mejor comprensión de esta cuestión, propongo descomponer el concepto de equidad a sus formas elementales, respetando la especificidad de su aplicación en el campo de la salud. En este sentido, solo a los efectos de la argumentación, consideremos que, tanto en el ideal rawls-seniano de un Estado de bienestar social democrático y eficiente como dispositivo redistributivo ${ }^{(18,23)}$, como en las utopías socialistas de una sociedad igualitaria, justa y solidaria $^{(60,61)}$, la equidad en salud se traduciría en cuatro componentes:

- Equidad en el estado de salud: los riesgos de enfermarse serían homogéneos para todos los grupos de población.

- Equidad en las condiciones de salud: todos los ciudadanos y ciudadanas estarían cubiertos por programas efectivos de promoción y protección de la salud.

- Equidad en el acceso a la atención de la salud: en un contexto de equidad social, sistemas y servicios de asistencia y recuperación de la salud se garantizarían a las personas por igual.

- Equidad en las prácticas de cuidado: efectividad tecnológica, humanización y calidad del cuidado estarían igualmente disponibles a toda la ciudadanía.

En el primer componente de la equidad en salud es necesario considerar que la igualdad ante los riesgos para la salud o la homogeneidad en la distribución de probabilidades de enfermarse y morir constituyen una posibilidad concreta solo en lo concerniente a factores de riesgo socioambientales. En términos 
epidemiológicos, esto sucede porque los riesgos para la salud no solo resultan de la acción de factores ambientales externos, sino también de vulnerabilidades y susceptibilidades individuales, además de las interacciones individuo-ambiente ${ }^{(56,63,64)}$. De allí surgen procesos inevitables de diferenciación de la salud (como funcionalidad vital) en todas las especies, más aún en los humanos, primates atravesados por el lenguaje, productores de cultura, dependientes de lazos sociales, en síntesis, animales políticos. Desde una perspectiva epidemiológica stricto sensu, el indicador global de esa inequidad respecto al estado de salud será mayor o menor desigualdad en la duración media de la vida (medida en años con calidad de vida), entre los diferentes agregados geopolíticos, económicos y sociales, lo que puede ser complementado por otros indicadores de morbilidad, mortalidad y uso de servicios de salud ${ }^{(80)}$. En este caso, en la medida en que la desigualdad en la situación de salud resulta de la mediación o interacción socioambiental, podemos considerar que se trata de una deuda sanitaria secundaria o indirecta.

El segundo y tercer componente del concepto de equidad en salud, indicados anteriormente, comparten una dinámica similar, en la medida en que constituyen el objeto de las políticas públicas de salud. Aquí, en ambos sentidos, la situación de iniquidad resultaría de la omisión del Estado en la promoción de la calidad de vida de los ciudadanos, que garantizaría derechos fundamentales como vivienda, seguridad, ambiente saludable, libertad política, educación y salud. En esos casos, se trata de una deuda social directa, resultante de la ausencia o limitación de programas y servicios de salud, que requeriría ser asumida y honrada por la sociedad a través de acciones y políticas de ampliación del acceso a los recursos disponibles y adecuados para mejorar las condiciones de salud de la población, cuya meta sería un acceso universal y ecuánime.

Esos tres componentes del problema de las desigualdades sociales y de las iniquidades en salud han sido objeto de profusa producción conceptual y empírica en varias realida- des y situaciones concretas ${ }^{(1,3,8,41,42,46,66,67)}$. Las desigualdades cualitativas en el acceso a tecnologías diagnósticas, asistenciales, preventivas y de rehabilitación, a su vez relacionadas con diferentes niveles de eficacia, efectividad $y$, principalmente, calidad humana del cuidado, son menos conocidas en sus determinantes y efectos. Eso nos lleva al cuarto componente de la equidad en salud, que propongo designar con el concepto de "calidad-equidad". La problemática de la calidad con equidad, en este caso, se sitúa en la intersección borrosa entre aspectos cuantitativos y cualitativos de la producción de asistencia de la salud, entre oferta y utilización de los servicios de salud en los actos de cuidado y en los itinerarios terapéuticos, al interior de los sistemas de salud. Propongo aquí tratarla como un desvío o derivación negativa de la atribución de calidad en la atención de la salud. Vista de esa manera, internalizada en las propias prácticas del cuidado en salud, el surgimiento de desigualdades en la calidadequidad revela otro orden de iniquidades, que se manifiestan en cuatro aspectos:

- La ruptura de la integralidad, parcialmente incumplida por el funcionamiento, todavía incipiente desde el punto de vista tecnológico, de sistemas de referencia y de contrarreferencia que seleccionan socialmente a los pacientes para los diferentes niveles de atención.

- La disponibilidad desigual de tecnologías diagnósticas, preventivas y terapéuticas, especialmente equipos, procedimientos y fármacos de última generación de alto costo y mayor eficacia (en algunos casos, este aspecto puede verse agravado por el fenómeno de la judicialización del derecho a la salud).

- Las formas de diferenciación positiva o negativa en el uso de tecnologías eficientes y resolutivas, en contextos y niveles equivalentes de atención, excluyendo, discriminando y segregando a pacientes de diferentes segmentos sociales u orígenes culturales.

- La calidad diferencial observada en los actos de atención de la salud, cuando observamos formas de diferenciación positiva o 
negativa en el tratamiento de los usuarios, bajo diversos formatos de sesgo selectivo, tales como invisibilización, segregación, discriminación, diferenciación por clase, género, etnia, generación o lugar de origen.

¿Cómo garantizar "calidad-equidad" en salud como derecho fundamental de todas las personas? En un sentido general, es necesario priorizar los elementos ético-políticos del cuidado, pues no sería moralmente justo y políticamente correcto excluir a nadie del acceso a una asistencia de calidad en salud. En sentido estricto, se intenta que el concepto de "calidad-equidad" sea un patrón universal de prácticas de salud, fundado sobre una noción determinada y específica de justicia social en todos los planos -desde el macroeconómico al macrosocial- como conquista política del derecho a la salud, más allá de las estrategias redistributivas del bienestar social. Incluso con las garantías legales y normativas típicas de las democracias constitucionales, ¿en qué dimensión se concreta este tipo de derecho?: ¿salud como estado vital?, ¿como conjunto de prácticas de cuidado?, ¿como valor y medida?; ¿en qué nivel?, ¿en todos los niveles?; ¿con qué grado de calidad?, ¿la mejor posible?; y ¿de qué manera?, ¿qué modelos de cuidado?, constituyen cuestiones abiertas. Veamos brevemente el caso particular del Brasil como ilustración de esa argumentación.

\section{NUEVAS DESIGUALDADES: EL CASO DE BRASIL}

A pesar de que hace 30 años que se implementó un sistema asistencial unificado -el Sistema Único de Salud (SUS) ${ }^{(86)}{ }_{-}$, en Brasil persisten profundas iniquidades en salud concentradas, sobre todo, en la calidad diferencial de los recursos socialmente destinados a la promoción de la salud ${ }^{(87)}$. Los recientes avances en el contexto sanitario brasileño permitieron que sujetos de clases y grupos sociales desfavorecidos -en general, residentes en áreas distantes de los centros urbanos, antes excluidos- consigan cada vez más acceder al SUS, en particular, a la atención primaria de la salud mediante la estrategia de Salud Familiar ${ }^{(86,88)}$. Sin embargo, aquellas personas con mayores necesidades y mayores grados de vulnerabilidad siguen enfrentando dificultades para utilizar los programas de promoción, protección y recuperación de la salud, principalmente, en los niveles secundario y terciario de atención, con una amplia disponibilidad para sectores sociales ya beneficiados con mejores condiciones de vida y con la cobertura de planes privados de salud $^{(89)}$. En el contexto brasileño se observan problemas vinculados al financiamiento, la gestión y la calidad del sistema público de salud, agudizados por la reciente crisis económica, social y política ${ }^{(90)}$. En el sector público de atención de la salud, en todo Brasil, los aspectos organizacionales de los programas y las instituciones de salud se constituyen en obstáculos materiales e institucionales que generan diferenciación, desigualdades y segregación, que dependen de disparidades de ingresos y de inserción social en el acceso a recursos asistenciales disponibles, además de la brecha en la información, determinada por diferenciales de género, generación, educación e ingresos ${ }^{(89,90)}$.

Así, a pesar de ser admitidos por el sistema, los sujetos de segmentos sociales vulnerados, con más necesidades de asistencia de calidad, sufren un nuevo orden de desigualdades, internalizadas en los propios actos de cuidado, resultantes de la estructura y funcionamiento del sistema y de la realización de prácticas asistenciales de poca efectividad y menor grado de humanización. Esos sujetos se ven en una situación de profunda iniquidad, en la condición de usuarios de categoría inferior en un sistema público de salud supuestamente universal. Una especulación razonable es que ese quiebre de la calidad-equidad, transformada en una nueva modalidad de "iniquidad internalizada", de naturaleza cualitativa, cotidiana, intrafuncional y camuflada, ha sido ejercida en distintos niveles y dimensiones mediante formas sutiles y culturalmente sensibles de relacionamiento intersubjetivo deshumano, segregador y discriminatorio. Lo aterrador de 
esa especulación es que, en nuestro país, la formación de competencias para producir y operar esas formas de iniquidad encuentra sus raíces y su reproducción en el propio sistema de educación formal(91) y en el proceso ideológico incorporado al entrenamiento y capacitación de personal técnico y profesional en salud ${ }^{(92)}$.

En Brasil, mientras se buscaba superar pacíficamente la salida de la dictadura militar de 1964-1985, en un contexto de crisis económica y social, se quiso crear un "Estado de bienestar social" en el seno de un capitalismo patrimonialista, opresivo y depredador, en una sociedad aún estructurada en el colonialismo, en la esclavitud y en el racismo, sin transformarla. Así, en el contexto actual de avance del ultraneoliberalismo en todo el mundo, terminamos con una democracia parcial, o democracia de baja-intensidad (como diría Boaventura de Sousa Santos)(61) en vista de la exclusión económica, social y política de un gran sector de la población. A pesar de ser el resultado de la restauración de un orden republicano precariamente negociado, el Estado brasileño falla en cumplir funciones básicas del Estado democrático moderno, establecidas desde su concepción en el inicio del siglo XIX como dispositivo capaz de redistribuir poder y riqueza, atenuando efectos de desigualdades económicas y desequilibrios políticos en el límite mínimo para garantizar la paz social. De esa forma, el Estado brasileño se confirma como un Estado de malestar social. Subfinanciado, ineficiente para conducir políticas públicas capaces de compensar las desventajas actuales y reparar deudas sociales históricas, los sectores estatales funcionan como una verdadera usina de transformación de desigualdades económicas en iniquidades sociales y políticas, sobre todo, en las áreas de seguridad, educación y salud.

\section{COMENTARIO FINAL}

A partir de la sistematización de conceptos y del modelado sintético propuestas en este texto, propongo la hipótesis de que este proceso amplio y complejo, de mutación de la naturaleza de las desigualdades económicas y sociales, termina produciendo nuevas formas de inequidades e iniquidades en salud. Un corolario de esa hipótesis es que, particularmente en países de economía periférica y democracias de baja-intensidad como Brasil, el propio Estado funciona como promotor e implementador de desigualdades, y actúa como principal agente social de transformación de las inequidades en iniquidades $^{(93)}$. En el caso específico de la salud, diversos estudios ${ }^{(94,95)}$ han producido evidencias robustas de que, en diversos contextos, incluso en Estados de bienestar social con mayor estabilidad política, la asignación de recursos públicos gubernamentales puede, directa o indirectamente, beneficiar a los segmentos más ricos de la sociedad.

En El capital en el siglo XXI, con base en una rigurosa econometría historiográfica, Piketty ${ }^{(96)}$ describe una tendencia secular de persistencia de las desigualdades, divididas en desigualdades de propiedad del capital y desigualdades de ingresos del trabajo, como fundamento estructural del sistema económico capitalista. En una obra más reciente, este autor titula la sumatoria de sus nuevos hallazgos como "le retour des inégalités"(29) al mostrar que el cambio de naturaleza del capitalismo tardío -que actualiza su base productiva con activos cognitivos y revisa sus formas de realización de la lucratividad mediante financiarización internacionalizada- corresponde a un aumento de las desigualdades extremas, que debería ser superado o compensado mediante políticas económicas y sociales. No obstante, en este contexto de hipercapitalismo globalizado, nos encontramos en una coyuntura política mundial dominada por una perversa combinación de fundamentalismo y oscurantismo, en contextos de ajustes económicos orientados por el neoliberalismo, productores de desigualdades sociales con impactos fuertemente negativos sobre la salud colectiva ${ }^{(97,98)}$.

A partir de ese referencial, y en línea con recientes revisiones de la cuestión teórica de las desigualdades en $\operatorname{salud}^{(97,98,99)}$, Julia Lynch $^{(100)}$ analiza lo que denomina el "enigma 
de la desigualdad resiliente". Según la autora, las instituciones creadas para reducir las desigualdades en salud en los Estados de bienestar de la Europa de posguerra, a partir de la década de 1980 se confrontaron con políticas económicas neoliberales. En vez de solucionar el problema de la desigualdad en el plano estructural, por medio de "remedios políticos" efectivos, se invirtió en procesos de gerenciamiento optimizado, supuestamente simples y eficaces. En esos países, la cuestión de las desigualdades en general se asumió como un problema solo legal, a ser resuelto en la esfera normativa, lo que permitía mantener, en el plano formal, un compromiso histórico con la equidad sin desafiar los fundamentos de la política tributaria que financia el Estado. En este contexto, la cuestión de las inequidades en salud se tornó una pauta política de centro-izquierda, que evitaba discutir la contradicción entre un orden de bienestar conservador-corporativista y el paradigma neoliberal que pasó a dominar Europa en la década de 1980. Para esta autora ${ }^{(100)}$ :

...el aumento de las desigualdades se tornó una característica más o menos permanente de la vida en la mayoría de las ricas democracias industrializadas de Europa en los últimos treinta años. Eso ocurrió a pesar [...] de un consenso creciente entre especialistas de que los niveles actuales de desigualdad son indeseables y hasta peligrosos. Mi trabajo ha sido estudiar la formulación de políticas en torno a las desigualdades en salud, que la mayoría de los especialistas en salud pública creen que están íntimamente ligadas a las desigualdades socioeconómicas, pero que los formuladores de políticas tienden a intentar resolver usando tipos de herramientas diferentes de aquellas proyectadas para impactar directamente en la distribución de ingresos y riqueza.

Enfocada en el plano de la economía en general, la propuesta de Piketty, desde un punto de vista teórico, puede ser considerada una nueva economía política, en la medida en que trata las desigualdades económicas como epifenómeno o subproducto del sistema económico y no como condición estructural del modo de producción capitalista. A su vez, en el campo de la salud, a pesar de la pretensión de formular una crítica teórica de lo que denomina "regímenes de inequidad", el análisis de Lynch se autorreferencia como una "political economy of wealth and health". Desde esa perspectiva, no esconde su objetivo de intentar resolver -en el plano de las políticas públicas, de modo eficiente y viable- problemas y contradicciones planteados por las inequidades en salud ante el sistema económico y social. Así, al tratar las desigualdades económicas (y sus contrapartidas políticas, sociales, gerenciales, societales y sanitarias) como efecto secundario e indeseables de procesos, ciclos y crisis económicas y políticas, susceptibles de soluciones capaces de, como dice Schrecker ${ }^{(98), ~ " t a m i n g ~}$ the inequality machine" (traducción libre: "domar la máquina de las desigualdades"), tanto Piketty como Lynch se posicionan dentro de los límites de la perspectiva funcionalista dominante en las epistemologías del norte, del linaje de Keynes-Rawls-Sen.

En un abordaje antagónico, como vimos anteriormente, diversos autores ${ }^{(16,31,56,97,98,102)}$ postulan el capitalismo como resultado de un proceso histórico global que, en el mundo contemporáneo, constituye un fenómeno de gran alcance y complejo. Por medio de relaciones estructurales y superestructurales, ese modo de producción se articula (interactúa, condiciona, determina, etc.) con la salud en distintos planos de realidad, mediante una serie de procesos, condiciones, determinantes y vectores. Para Sell \& Williams ${ }^{(102)}$, la macroeconomía del mundo globalizado, dominada en la actualidad por el neoliberalismo conservador, afecta profundamente la gobernanza del campo de la salud, en políticas y acciones diversas, como programas de austeridad, comercio internacional, inversiones en salud, industria farmacéutica y de equipamientos, seguridad alimentaria y consumo de productos ultraprocesados. Por lo tanto, según estos autores ${ }^{(102)}$, es necesario elaborar una comprensión del capitalismo "como estructuralmente patogénico, 
con impactos negativos en la salud humana", y encarar ese modo de producción global y de gran alcance como generador (y resultante) de desigualdades económicas, inequidades sociales e iniquidades en salud, como ningún otro sistema productivo en la historia humana. La sobredeterminación de los efectos estructurales profundos y subyacentes del capitalismo sobre la salud, y de la salud en el modo de producción se evidencia en múltiples escalas, e implica nuevos desafíos teóricos, científicos y políticos para el campo de la salud.

Por último, con base en el argumento de este ensayo y de acuerdo con Beckfield et al. ${ }^{(101)}$ y Sell \& Williams ${ }^{(102)}$, es pertinente afirmar que, en Estados de malestar social como Brasil, en esta coyuntura actual, el incremento de las desigualdades extremas promueve mutaciones y variaciones en las formas elementales de desigualdad, genera nuevas modalidades de inequidades sociales $y$, en consecuencia, nuevas formas de iniquidades en todos los espacios de diferenciación, incluyendo el campo de la salud. En este contexto, las desigualdades, inequidades e iniquidades paradójicamente crecen en la medida en que aumenta la capacidad resolutiva de las tecnologías en salud disponibles y se amplía la cobertura formal del sistema de salud. Incluso desde una perspectiva distributiva, el componente de desigualdad en los riesgos de enfermarse y morir puede ser indicador de una deuda sanitaria indirecta. Sin embargo, además de las desigualdades ante los riesgos para la salud, los componentes de tal deuda social pueden referirse también a diferenciales en la promoción y protección de la salud; en la cobertura asistencial; en la disponibilidad de tecnologías seguras, accesibles y efectivas; y en iniquidades en la calidad del cuidado. En este sentido, la persistencia y la profundización del componente "sanitario" de esa deuda social primaria, con el surgimiento de nuevas formas de iniquidades, puede significar el debilitamiento y retroceso del compromiso político de la sociedad brasileña con relación a la garantía del derecho universal a la salud. Para que eso no ocurra, será necesario una intensa y urgente lucha política para retomar el Estado, reafirmando su carácter de dispositivo democrático comprometido con el progreso social, ampliando y renovando alianzas con todas las fuerzas sociales y movimientos políticos que, en los últimos 40 años, de diversas formas ha contribuido a la consolidación y ampliación de las políticas públicas de salud, que dieron como resultado la mejora de la situación de salud en Brasil.

\section{AGRADECIMIENTOS}

En las diferentes secciones, este texto organiza anotaciones de dos décadas de oportunidades de debates: el "Workshop on Inequities in Health", promovido por la London School of Hygiene and Tropical Medicine y por la Embajada de Brasil en Londres, el 14 de septiembre de 1999; el Seminario "El Desafío de la Equidad en Salud", de la Sociedad Argentina para la Equidad en Salud, en Buenos Aires, Argentina, el 6 de abril de 2000; el $V$ Congresso Brasileiro de Epidemiología, realizado por la Associação Brasileira de Saúde Coletiva (ABRASCO), en Curitiba, en marzo de 2002; el Seminário "Rediscutindo a questão da determinação social da saúde", organizado por el Centro Brasileiro de Estudos de Saúde (CEBES), en Rio de Janeiro, el 22 de mayo de 2009; y en el Seminario "Desigualdades en salud: Nuevos aportes histórico-críticos", en el Doctorado en Salud Colectiva de la Universidad Nacional de Lanús, Buenos Aires, el 2 de agosto de 2018.

Agradezco especialmente a Jairnilson Silva Paim y Ligia Vieira da Silva, mis colegas del Instituto de Saúde Coletiva de la Universidade Federal da Bahia (ISC-UFBA), por el diálogo crítico, generoso y riguroso que permitió la consistencia de la argumentación. Agradezco además a Pedro Luis Castellanos, Alberto Pellegrini Filho, Moisés Goldbaum, Hugo Spinelli, Ichiro Kawachi, Roberto Passos Nogueira, Maurício Barreto, César Victora, Eduardo Mota y Luis Eugenio de Souza por las críticas y sugerencias a las diferentes partes y versiones del manuscrito. A Juan Samaja y Norberto Dachs (in memoriam). 


\section{REFERENCIAS BIBLIOGRÁFICAS}

1. Almeida-Filho N. Desigualdades de salud en función de las condiciones de vida: análisis de la producción científica en América Latina y el Caribe y bibliografía anotada. Washington DC: OPS; 1999.

2. Organización Panamericana de la Salud. Macrodeterminantes de la Inequidad en Salud [Internet]. Washington, DC: OPS; 2000 [citado 2 nov 2019]. Disponible en: https://tinyurl.com/yaxcdjdt.

3. Almeida-Filho N, Kawachi I, Filho AP, Dachs JN. Research on health inequalities in Latin America and the Caribbean: bibliometric analysis (1971-2000) and descriptive content analysis (1971-1995). American Journal of Public Health. 2003;93(12):2037-2043. doi: 10.2105/ ajph.93.12.2037.

4. Breilh J. La determinación social de la salud como herramienta hacia una nueva salud pública (salud colectiva). Revista Faculdad Nacional de Salud Pública. 2013;31(Supl. 1):S13-S27.

5. Wagstaff A, van Doorslaer E. Income inequality and health: what does the literature tells us? Annual Review of Public Health. 2000;21:543-567. doi: 10.1146/annurev. publhealth.21.1.543.

6. Wilkinson RG. Unhealthy societies: the afflictions of inequality. London: Routledge; 1996.

7. Wilkinson R, Marmot M, (eds.). Social determinants of health: The solid facts. Copenhagen: World Health Organization; 2003.

8. Berkman L, Kawachi I. Social epidemiology. New York: Oxford University Press; 2000.

9. Thoits P. Stress and health: major findings and policy implications. Journal of Health and Social Behavior. 2010;51(Suppl):S41-S53. doi: 10.1177/00221465 10383499 .

10. Marmot M. The status syndrome: How social standing affects our health and longevity. New York: Owl Books; 2005.

11. Coburn D. Income inequality, social cohesion and the health status of populations: the role of neo-liberalism. Social Science \& Medicine. 2000;51(1):135-146. doi: 10.1016/s0277-9536(99)00445-1.

12. Diederichsen F, Evans T, Whitehead M. Chapter 2: the social basis of disparities. In: Evans T, Whitehead $M$, Diderichsen F, Bhuiya A, Wirth M, (eds.). Challenging inequities in health. London: Oxford University Press; 2001. p. 53-64.

13. Krieger $\mathrm{N}$. Theories for social epidemiology in the 21st century: an ecosocial perspective. International Journal of Epidemiology. 2001;30(4):668-677. doi: 10.1093/ije/30.4.668.

14. Samaja J. Epistemología y metodología: Elementos para una teoría de la investigación científica. Buenos Aires: EUDEBA; 2005.
15. Samaja J. Epistemología de la Salud. Buenos Aires: EUDEBA; 2005.

16. Habermas J. Direito e democracia: entre facticidade e validade. Rio de Janeiro: Tempo Brasileiro; 2003.

17. Rawls J. A theory of justice. Cambridge: Harvard University Press; 1971.

18. Rawls J. Justice as fairness: a restatement. Cambridge: Harvard University Press; 2001

19. Rawls J. Political Liberalism. New York: Columbia University Press; 2005.

20. Mill JS. Utilitarianism. Cambridge: Hackett Publishing Company, 2001

21. Hart HLA. Rawls on liberty and its priority. In: Daniels N, (ed.). Reading Rawls. Stanford: Stanford University Press; 1989.

22. Sen A. On economic inequality. New York: Oxford University Press; 1981.

23. Sen A. Inequality reexamined. New York: Oxford University Press; 1992.

24. Foster J, Sen A. On economic inequality after a quarter century. In: Sen A. On economic inequality (Expanded Edition). New York: Oxford University Press, 1997. p. $121-220$

25. Sen A. ¿Por qué la equidad en salud? Revista Panamericana de Salud Pública. 2002;11(5/6):302-309.

26. Marx K. Crítica ao programa de Gotha. In: Marx K, Engels F. Textos. São Paulo: Alfa-Omega; 1977.

27. Marx K. O capital: crítica da economia política. São Paulo: Abril Cultural; 1984

28. Bourdieu P. La distinción: Criterios y bases sociales del gusto. Madrid: Taurus; 1988.

29. Piketty T. Capital et idéologie. Paris: Editions du Seuil; 2019

30. Sousa-Santos B. Introducción a las epistemologías del sur. En: Meneses MP, Bidaseca K, (coords.). Epistemologías del sur. Buenos Aires: CLACSO-Coimbra; 2018. p. 25-64.

31. Sousa-Santos B. O fim do império cognitivo: a afirmação das epistemologias do sul. Belo Horizonte: Autêntica; 2019.

32. Almeida Filho N. Towards a unified theory of healthdisease: II - Holopathogenesis. Revista de Saúde Pública. 2014;48(2):192-205. doi: 10.1590/S0034-8910. 2014048005196.

33. Whitehead $M$. The concepts and principles of equity and health. International Journal of Health Services. 1992;22(3):429-445. 
34. Whitehead M. A typology of actions to tackle social inequalities in health. Journal of Epidemiology and Community Health. 2007;61(6):473-478.

35. Ossanai J. Reformas contemporáneas en el campo de la salud: en busca de la equidad. Rockville: Technical Resources International Inc.; 1994.

36. Metzger X. Conceptualización e indicadores para el término equidad y su aplicación en el campo de la salud. Washington: OPS; 1996.

37. Bambas A, Casas JA. Assessing equity in health: conceptual criteria. En: Equity and health: Views from the Pan American Sanitary Bureau. Washington DC: PanAmerican-Health-Organization; 2001. Ocassional Publication No 8, p. 12-21.

38. Daniels N, Kennedy B, Kawachi I. Is inequality bad for our health? Boston: Beacon Press; 2000.

39. Peter $F$, Evans T. Ethical dimensions of health equity. En: Evans T, Whitehead M, Diderichsen F, Bhuiya A, Wirth $M$ (ed.). Challenging inequities in health: from ethics to action. London: Oxford University Press; 2001. p. 25-33.

40. Spinelli H. Condiciones de Salud y Desigualdades Sociales: historias de iguales, desiguales y distintos. En: Críticas e atuantes: Ciências Sociais e Humanas em Saúde na América Latina. Minayo MC, Coimbra C, (org.). Rio de Janeiro: Editora Fiocruz; 2005. p. 315-332.

41. Macinko JA, Starfield B. Annotated Bibliography on Equity in Health, 1980-2001. International Journal for Equity in Health. 2002;1(1):1-20. doi: 10.1186/14759276-1-1.

42. Macinko JA, Shi L, Starfield B, Wulu Jr JT. Income inequality and health: a critical review of the literature. Medical Care Research and Review. 2003;60(4):407452. doi: 10.1177/1077558703257169.

43. International Society of Equity in Health (ISEqH) [Internet]. Home [citado 10 jun 2019]. Disponible en: http://www.iseqh.org.

44. Vieira da Silva LM, Almeida-Filho N. Equidade em saúde: uma análise crítica de conceitos. Cadernos de Saúde Pública. 2009;25(Supl 2):S217-S226. doi: 10.1590/S0102-311X2009001400004.

45. Wagstaff A, Van Doorslaer E. Measuring inequalities in health in the presence of multiple-category morbidity indicators. Health Economics. 1994;3(4):281-289. doi: 10.1002/hec.4730030409.

46. Alazraqui M, Mota E, Spinelli H. El abordaje epidemiológico de las desigualdades en salud a nivel local. Cadernos de Saúde Pública. 2007;23(2):321-330.

47. Bommier A, Stecklov G. Defining health inequality: why Rawls succeeds where social welfare theory fails. Journal of Health Economics. 2002;21(3):497-513. doi: 10.1016/S0167-6296(01)00138-2.
48. Kawachi I, Subramanian S, Almeida-Filho N. A glossary for health inequalities. Journal of Epidemiology and Community Health. 2002;56(9):647-652. doi: 10.1136/jech.56.9.647.

49. Braveman P. Health disparities and health equity: Concepts and measurement. Annual Review of Public Health. 2006;27:167-194. doi: 10.1146/annurev.publhealth.27.021405.102103

50. Braveman P. What are health disparities and health equity? We need to be clear. Public Health Reports. 2014;129(Supl 2):S5-S8. doi: $10.1177 / 00333549141291$ S203.

51. Arcaya MC, Arcaya AL, Subramanian SV. Desigualdades en salud: definiciones, conceptos y teorías. Pan American Journal of Public Health. 2015;38(4):261-271.

52. Almeida-Filho N. Modelos de determinação social das doenças crônicas não-transmissíveis. Ciência \& Saúde Coletiva. 2004;9(4):865-884. doi 10.1590/S141381232004000400009

53. Almeida-Filho N. A problemática teórica da determinação social da saúde (nota breve sobre desigualdades em saúde como objeto de conhecimento). Saúde em Debate. 2009;33(83):349-370.

54. Wainwright SP, Forbes A. Philosophical problems with social research on health inequalities. Health Care Analysis. 2000;8(3):259-277. doi: 10.1023/A:1009479515070.

55. Breilh J. El género entre fuegos: inequidad y esperanza. Quito: Centro de Estudios y Asesoría en Salud 1996.

56. Breilh J. Epidemiologia Crítica: Ciência Emancipadora e Interculturalidad. Buenos Aires: Lugar Editorial; 2003.

57. Breilh J. La determinación social de la salud como herramienta de transformación hacia una nueva salud pública (salud colectiva). Revista Facultad Nacional de Salud Pública. 2013;31(Supl 1):S13-S27.

58. Breilh J. Epidemiología del siglo XXI y ciberespacio: repensar la teoría del poder y la determinación social de la salud. Revista Brasileira deEpidemiologia. 2015;18(4):9659745. doi: 10.1590/1980-5497201500040025.

59. Gatrell AC, Popay J, Thomas C. Mapping the determinants of health inequalities in social space: Can Bourdieu help us?. Health Place. 2004;10(3):245-257. doi 10.1016/j.healthplace.2003.09.005.

60. Heller A. Além da justiça. Rio de Janeiro: Civilização Brasileira; 1998.

61. Sousa-Santos B. Para uma revolução democrática da justiça. São Paulo: Cortez; 2007.

62. Asada Y. A framework for measuring health inequity. Journal of Epidemiology and Community Health. 2005;59(8):700-705. doi: 10.1136/jech.2004.031054. 
63. Ayres JRCM. Acerca del riesgo: Para comprender la epidemiología. Buenos Aires: Lugar Editorial; 1997.

64. Ayres JRCM, Calazans GJ, Saletti Filho HC, Franca Junior I. Risco, vulnerabilidade e práticas de prevenção e promoção da saúde (2009). En: Tratado de saúde coletiva. São Paulo: HUCITEC-FIOCRUZ; 2009.

65. Testa M. Saber en salud: la construcción del conocimiento. Buenos Aires: Lugar Editorial; 1997.

66. Marmot, M. Social determinants of health inequalities. Lancet. 2005;365(9464):1099-1104. doi: 10.1016/ S0140-6736(05)71146-6.

67. World Health Organization, Commission on Social Determinants of Health. Closing the gap in a generation: Health equity through the social determinants of health [Internet]. Geneva: World Health Organization; 2008 [citado 10 jun 2019]. Disponible en: https://tinyurl.com/ ycg9k8vx

68. Raphael D. Tackling Health Inequalities: Lessons from International Experiences. Toronto: Canadian Scholars' Press; 2012.

69. Krieger N, Alegría M, Almeida-Filho N, Da Silva JB, Barreto ML, Beckfield J, Berkman L, Birn AE, Duncan BB, Franco $S$, et al. Who, and what, causes health inequities? Reflections on emerging debates from an exploratory Latin American/North American workshop. Journal of Epidemiology \& Community Health. 2010;64(9):747749. doi: 10.1136/jech.2009.106906.

70. Braveman P, Egerter S, Williams D. The social determinants of health: coming of age. The Annual Review of Public Health. 2011;32:381-98. doi: 10.1146/annurevpublhealth-031210-101218.

71. Braveman P, Gottlieb L. The social determinants of health: it's time to consider the causes of the causes. Public Health Reports. 2014;129(S2):19-31. doi: 10.1177/00333549141291S206.

72. Rocha PR, David HM. Determinação ou Determinantes? Uma discussão com base na Teoria da Produção Social da Saúde. Revista da Escola de Enfermagem da USP. 2015;49(1):129-135.

73. Borde E, Hernández M. Revisiting the social determinants of health agenda from the global South. Global Public Health. 2019;14(6-7):847-862. doi: 10.1080/17441692.2018.1551913.

74. Franko W, Tolbert C, Witko C. Inequality, self-interest, and public support for "Robin Hood" tax policies. Political Research Quarterly. 2013;66(4):923-937. doi: $10.1177 / 1065912913485441$.

75. Waitzkin H, Iriart C, Estrada A, Lamadrid S. Social medicine then and now: Lessons from Latin America. American Journal of Public Health. 2001;91(10):15921601. doi: 10.2105/ajph.91.10.1592.

76. Pearce N. Epidemiology in Latin America: An opportunity for a global dialogue. Journal of Epidemiology \&
Community Health. 2008;62(9):762-763. doi: 10.1136/ jech.2008.078659.

77. Laurell AC. La salud-enfermedad como proceso social. Revista Latinoamericana de Salud. 1982;2(1):7-25.

78. Laurell AC. Social analysis of collective health in Latin America. Social Science \& Medicine. 1989;28(11):11831191. doi: 10.1016/0277-9536(89)90011-7.

79. Gonçalves R, Ayres JR (org.), Santos L (org.). Saúde, Sociedade e História: Uma revisita às contribuições de Ricardo Bruno Mendes-Gonçalves. São Paulo: Hucitec; 2017.

80. Castellanos PL. Epidemiologia, saúde pública, situação de saúde e condições de vida. Considerações conceituais. En: Barata RB. Condições de vida e situações de saúde. Rio de Janeiro: ABRASCO; 1997. p. 31-75.

81. Castellanos PL. Perfis de mortalidade, nível de desenvolvimento e iniquidades sociais na região da Américas. En: Barata RB, Barreto $\mathrm{ML}$, Almeida Filho N, Veras RP (orgs.). Equidade e saúde: contribuições da epidemiologia. Rio de Janeiro: FIOCRUZ, ABRASCO; 1997. p. $137-162$

82. UN Millennium Project. Investing in development: a practical plan to achieve the Millennium Development Goals [Internet]. New York: United Nations; 2005 [citado 10 jun 2019]. Disponible en: https://tinyurl.com/ ybs9jvty.

83. Murray CL, Lopez A. The Global Burden of Disease. Cambridge: Harvard University Press; 1996.

84. Vasconcellos M. Serviços de Saúde: uma revisão de processos de regionalização, análises de padrões espaciais e modelos de localização. En: Najar AL, Marques E (orgs.). Saúde e espaço: estudos metodológicos e técnicas de análise. Rio de Janeiro: Editora FIOCRUZ; 1998. p. 63-93.

85. Nery M. A dívida social. Conjuntura Econômica. 2002;56(2):38-39.

86. Paim J, Travassos C, Almeida C, Bahia L, Macinko J. The Brazilian health system: history, advances, and challenges. The Lancet. 2011;377(9779):1778-1797. doi: 10.1016/S0140-6736(11)60054-8.

87. Nunes A, Santos, JRS, Barata RB, Vianna SM. Medindo as desigualdades em saúde no Brasil: uma proposta de monitoramento. Brasil: OPS/IPEA; 2001.

88. Victora CG, Aquino EM, do Carmo Leal M, Monteiro CA, Barros FC, Szwarcwald CL. Maternal and child health in Brazil: Progress and challenges. The Lancet. 2011;377(9780):1863-1876. doi: 10.1016/S01406736(11)60138-4

89. Macinko J, Lima-Costa MF. Erratum: Horizontal equity in health care utilization in Brazil, 1998-2008. International Journal for Equity in Health. 2012;11(1):33. doi: 10.1186/1475-9276-11-33 
90. Rasella D, Basu S, Hone T, Paes-Sousa R, Ocké-Reis CO, Millett C. Child morbidity and mortality associated with alternative policy responses to the economic crisis in Brazil: A nationwide microsimulation study. PLoS Med. 2018;15(5):e1002570. doi: 10.1371/journal. pmed. 1002570 .

91. Almeida-Filho N. Social inequality and human development: Intertwined cycles of perversion in education in contemporary Brazil. Encounters in Theory and History of Education. 2015;16:84-100. doi: 10.24908/ eoe-ese-rse.v16i0.5970.

92. Almeida-Filho N. Higher education and health care in Brazil. The Lancet. 2011;377(9781):1898-1900.

93. Costa S. Desigualdades, Interdependência e Políticas Sociais no Brasil. En: Pires RR (org.). Implementando desigualdades: reprodução de desigualdades na implementação de políticas públicas [Internet]. Rio de Janeiro: Instituto de Pesquisa Econômica Aplicada; 2019 [citado 10 jun 2019]. Disponible en: https://tinyurl.com/yc8ge2a2.

94. Wagstaff A. Benefit-incidence analysis: Are government health expenditures more pro-rich than we think?. Health Economy. 2012;21(4):351-366. doi: 10.1002/hec.1727.

95. Griffin S, Love-Koh J, Pennington B, Owen L. Evaluation of intervention impact on health inequality for resource allocation. Medical Decision Making. 2019;39(3):171. doi: 10.1177/0272989X19829726.
96. Piketty T. El capital en el siglo XXI. Madrid: Fondo de Cultura Económica; 2015.

97. Schrecker T. Neoliberalism and Health: The linkages and the dangers. Sociology Compass. 2016;10(10):952971. doi: $10.1111 /$ soc4.12408.

98. Schrecker T. Globalization, austerity and health equity politics: Taming the inequality machine, and why it matters. Critical Public Health. 2016;26(1):4-13. doi: 10.1080/09581596.2014.973019.

99. Pickett KE, Wilkinson RG. Income inequality and health: A causal review. Social Science \& Medicine. 2015;128:316 326. doi: 10.1016/j.socscimed.2014.12.031.

100. Lynch J. Regimes of inequality: The political economy of health and wealth. Cambridge: Cambridge University Press; 2020.

101. Beckfield J, Bambra C, Eikemo T, Huijts T, MCnamara $C$, Wendt $C$. An institutional theory of welfare state effects on the distribution of population health. Social Theory \& Health. 2015;13(3):227-244. doi: 10.1057/sth.2015.19.

102. Sell SK, Williams OD. Health under capitalism: a global political economy of structural pathogenesis. Review of International Political Economy. 2020;27(1):125. doi: 10.1080/09692290.2019.1659842.

\section{FORMA DE CITAR}

Almeida-Filho N. Desigualdades en salud: nuevas perspectivas teóricas. Salud Colectiva. 2020;16:e2751. doi: 10.18294/ sc. 2020.2751.

Recibido: 2 mar 2020| Aprobado: 7 jun 2020 | Publicado en línea: 20 jun 2020

Esta obra está bajo una licencia de Creative Commons Reconocimiento-NoComercial 4.0 Internacional. Reconocimiento - Permite copiar, distribuir y comunicar públicamente la obra. A cambio, se debe reconocer y citar al autor original. No Comercial - Esta obra no puede ser utilizada con finalidades comerciales, a menos que se obtenga el permiso.

https://doi.org/10.18294/sc.2020.2751

Este artículo fue traducido del portugués por Viviana Martinovich. 